\title{
Progress in the Development of Single-Phase Magnetoelectric Multiferroic Oxides
}

\author{
Jae-Hyeon Cho and Wook Jo ${ }^{\dagger}$
}

Department of Materials Science and Engineering \& Jülich-UNIST Joint Leading Institute for Advanced Energy Research (JULIA), Ulsan National Institute of Science and Technology (UNIST), Ulsan, Republic of Korea, 44919

\section{단일상 자기전기 다강성 산화물의 연구동향}

\author{
조재현, 조욱 \\ 울산과학기술원 신소재공학과 및 JULIA 연구센터
}

(Received August 8, 2021; Revised August 26, 2021; Accepted August 26, 2021)

\begin{abstract}
Magnetoelectric (ME) multiferroics manifesting the coexistence and the coupling of ferromagnetic and ferroelectric order are appealing widespread interest owing to their fascinating physical behaviors and possible novel applications. In this review, we highlight the progress in single-phase ME multiferroic oxides research in terms of the classification depending on the physical origins of ferroic properties and the corresponding examples for each case, i.e., material by material, along with their ME multiferroic properties including saturation magnetization, spontaneous polarization, (anti)ferromagnetic/ferroelectric transition temperature, and ME coefficient. The magnetoelectrically-active applications of high expectancy are presented by citing the representative examples such as magnetoelectric random-access-memory and multiferroic photovoltaics. Furthermore, we discuss how the development of ME multiferroic oxides should proceed by considering the current research status in terms of developed materials and designed applications. We believe that this short review will provide a basic introduction for the researchers new to this field.
\end{abstract}

Keywords: Single-phase multiferroics, Magnetoelectric coupling, Ferromagnetism/ferromagnetic oxides, Ferroelectricity/ferroelectric oxides

†Corresponding Author: wookjo@unist.ac.kr 


\section{1. 서론}

강성이란 외부에서 작용하는 힘이 없는 상태에 서도 대응되는 자발적인 물리량을 가지는 현상으 로, 작용하는 힘과 물리량의 종류에 따라 강자성 (ferromagnetism), 강유전성(ferroelectricity), 강탄성 (ferroelasticity)으로 구별하여 정의된다. 강성은 가장 오랫동안 연구되고 있는 물리적 현상 중 하나이며, 최근 두가지 이상의 강성이 단일상에서 공존 및 결합 되어있 는 현상과 관련하여 많은 연구가 다방면으로 진행되고 있다. ${ }^{1-3)}$ 다강체(multiferroics)란 이러한 현상을 띠는 물질로, 이미 강유전과 강탄성이 공존 및 결합된 현상은 압전(piezoelectricity)라는 이름으로 지난 100여년의 세 월 동안 학문적으로 또 다양한 응용으로 연구되어왔다. ${ }^{4}$ 반면, 강자성과 강유전성이 공존하는 형태인 자기전기 (magnetoelectric, ME) 다강체는 내재된 물리적 메커 니즘의 특이성 및 차세대 전자소자로의 활용 가능성으 로 인해 비교적 최근에 이르러서야 비로소 본격적으로 조명되고 있다. ${ }^{5-9)}$ 자기전기 다강체 개발의 필요성이 대 두되는 이유 중 하나로, 자기전기결합 (ME coupling) 효과를 꼽을 수 있다. ${ }^{10-12)}$ 자기전기결합 효과는 단순 히 강자성과 강유전성이 공존하는 것을 넘어, 상호작용 을 하는 현상을 일컫는다. 즉, 외부 자기장을 가해주어 강유전 분극(ferroelectric polarization)을 제어하거나 (정 자기전기결합 효과), 외부 전기장을 걸어주었을 때 자화 모멘트(magnetic moment)의 제어 (역 자기전기 결합 효과)가 가능한 현상을 일컫는다. 강자성과 강유전 성의 공존과 함께 이러한 결합 현상을 활용한다면, 기존 물질의 한계로 인해 연구개발에 난항을 겪고있는 고집 적/저전력 비휘발성 메모리, 고효율 태양광발전, 자기장 으로 제어가 가능한 인공근육 및 약물전달체계 등의 차 세대 소자 개발에 돌파구가 되어줄 것이라 기대된다. ${ }^{13-}$ 16)

자기전기결합 효과와 관련된 첫 이론적 논의는 1894 년에 Curie가 발표한 논문인 것으로 알려져 있다. ${ }^{17)}$ 자 기전기 다강성을 처음 실험적으로 보고한 것은 1960년 대에 $\mathrm{Cr}_{2} \mathrm{O}_{3}$ 단결정에서 선형 자기전기결합현상을 측정
한 논문이었으나, 보고된 자기전기 다강성(즉, 자화 모 멘트, 강유전분극, 자기전기결합 상수, 구동온도 등) 이 낮아서 큰 관심을 불러일으키지 못했다. ${ }^{18,19)}$ 이후에 도 여러 단일상, 압전/자왜 복합체 등 다강성 물질을 개 발하기 위한 다양한 연구가 발표되었으나, 앞서 언급 된 차세대 전자 소자로 응용하기 위한 요건을 충족시키 지 못하는 실정이었다. ${ }^{20-23)}$ 자기전기 다강체 연구는 단 일상에서 상당한 반강자성(antiferromagnetism)/강 유전 특성과 함께 자기전기결합 현상을 보인 $\mathrm{BiFeO}_{3}$ 와 $\mathrm{TbMnO}_{3}$ 가 2003년에 발표되면서 큰 전환점을 맞이 하게 된다 (Fig. 1). ${ }^{24,25)}$ 이를 기점으로 페로브스카이트 (perovskite) 구조와 관련된 조성뿐 아니라, 헥사페라이 트(hexaferrite), 스피넬 페라이트(spinel ferrtie), 오리 빌리어스(Aurivillius) 등 여러 구조를 기반으로 한 연구 가 폭발적으로 증가하였다. ${ }^{26-31)}$ 이에 따라 전이금속과 희토류를 도핑/치환하는 등의 실험 및 그 결과를 물리적 으로 풀어내기 위한 이론적 접근 등의 계산이 많이 발표 되었으나, 그럼에도 불구하고 상온 단일상 강자성/강유 전 자기전기 다강성을 나타내는 물질은 다른 종류의 다 강체와는 달리 여전히 매우 희귀한 편이다. ${ }^{32-34)}$

강자성과 강유전성이 단일상에서 공존하기 힘든 원인 을 규명하기 위해 다각도로 분석된 의견들이 제시되었 는데, 현재 보편적으로 받아들여지고 있는 주장은 다음 과 같다. ${ }^{35)}$ 첫째, 강자성과 강유전성이 발현되기 위한 기원이 서로 모순되기 때문이다; 강자성은 $\mathrm{d}$ 또는 $\mathrm{f}$ 오 비탈(orbital)에 홀전자(unpaired electron)가 존재해 야 하지만, 일반적인 변위형 강유전성은 d 오비탈에 전 자가 존재하지 않아야 발현된다. 둘째, 보편적으로 나타 나는 강자성체와 강유전체의 저항이 매우 상반되기 때 문이다; 강자성체는 저항이 매우 낮은 도체이지만, 강유 전체는 높은 저항을 지니는 부도체이다. 마지막으로는 각각의 강성이 발현될 수 있는 결정구조의 비교를 통해 설명 가능하다; 강자성의 경우엔 시간 역전 대칭(time reversal symmetry)을, 강유전성의 경우는 공간 반전 대칭(spatial inversion symmetry)을 깰 수 있어야 한 다. 즉, 강자성과 강유전성을 동시에 수반하는 다강성의 발현을 위해서는 두 조건을 모두 만족하여야 한다. 그러 


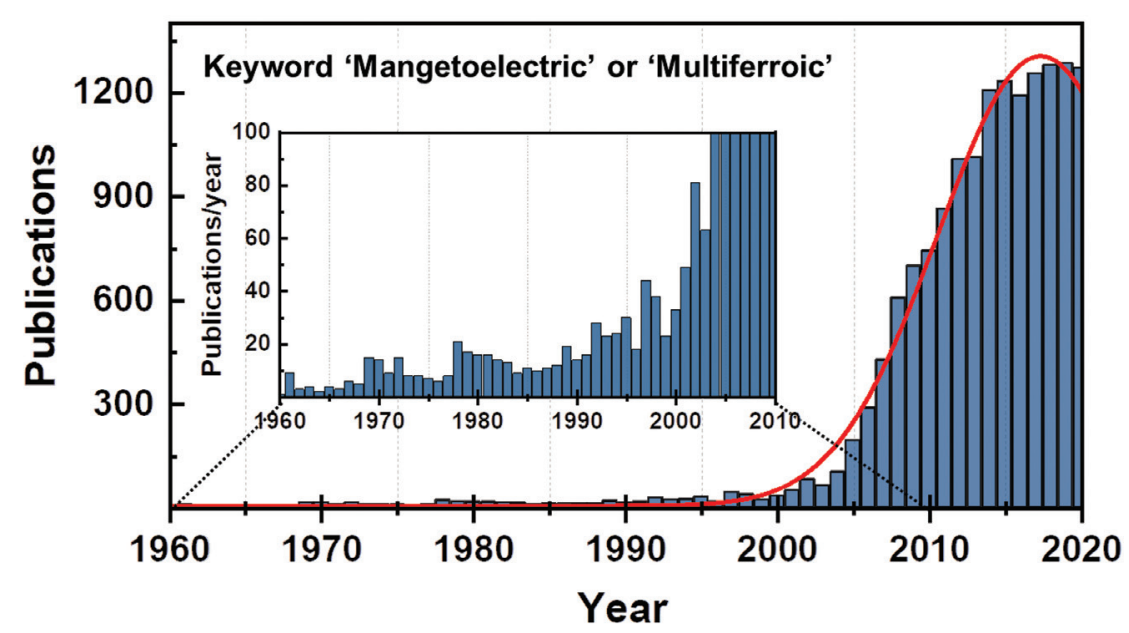

Fig. 1. Progress in magnetoelectric multiferroic research in terms of publications according to Web of Science ${ }^{\mathrm{TM}}$ (https:// apps.webofknowledge.com) ${ }^{18)}$.

나, 상기 두가지 경우를 만족시키는 점군은 13 개뿐이다 (1, 2, 2', m, m', 3, 3m', 4, 4m'm', m'm2', m'm'2', 6 , and $\left.6 \mathrm{~m}^{\prime} \mathrm{m}^{\prime}\right)$. 이와 같이 여러 제약이 있음에도 불구 하고, 상온 이상에서 자기전기결합 다강성을 나타내는 단일상 물질은 여러 방면에서 내재 가치가 크기 때문에 여전히 많은 관심을 받고 있다.

본 리뷰 논문에서는 우선 단일상 자기전기 다강체를 분류하는 가장 보편적인 체계를 기술한 뒤, 각 분류에 해당하는 대표적인 물질을 현재까지 밝혀진 메커니즘 및 자기전기 다강성(강자성/강유전성 전이온도, 포화 자 화값, 강유전 자발 분극 등)과 함께 살펴볼 것이다. 다음 으로는 자기전기결합 다강성을 활용한 대표적인 소자의 연구 동향에 대해서 간략히 언급하며, 개발된 다강성 물 질을 활용한 소자 구현의 진척도와 문제점을 논의해 보 고자 한다. 이를 바탕으로 상온 단일상 강자성/강유전 자기전기 다강성을 지니는 물질의 개발을 위해 나아가 야할 방향을 논의 함으로써 리뷰 논문을 끝맺고자 한다.

\section{2. 본론}

모든 강자성은 오비탈 내의 홀전자 유무에 따른 자기 스핀의 존재와 그들간 교환 상호작용에서 기인하는 것
으로 잘 알려져 있으나, 강유전성의 경우는 변위형이나 전하정렬 강유전체를 포함하는 일반적인 부류과 지알 로신스키-모리야(Dzyaloshinskii-Moriya, DM) 상호 작용 등의 특정적인 자기 스핀 교환 상호작용에서 기인 하는 일반적이지 않은 부류로 나뉘어 구별된다. ${ }^{36,37)}$ 이 러한 각 강성의 기원을 고려하며 가장 보편적으로 단일 상 자기전기 다강체를 분류하는 체계는 자기 스핀 유도 강유전성의 유무를 통해 Type I, II 로 나누는 것이다 (Fig. 2) ${ }^{38)}$ Type I 다강체는 강자성과 강유전성의 발현 기원이 완전히 독립적으로 존재하는 형태이다. 즉, 전통 적인 강유전체와 강자성체의 뛰어난 특성을 동시에 확 보할 수 있다는 가능성을 지니고 있기 때문에, 소자 구 현을 목표로 하는 다강체 연구에 가장 부합하는 형태이 다. 하지만 앞서 언급한 바와 같이, 강자성과 강유전성 이 단일상에서 공존하는 현상은 매우 드문 경우이며, 실 제로 대부분의 Type I 다강체는 강자성/강유전성 전 이 온도(큐리 온도, Curie temperature)가 상온 이하거 나 반강자성과 강유전성이 공존하는 형태이다. 또한 각 각의 강성 발현 기원이 독립적으로 존재하기 때문에, 자 기전기결합이 느슨하여 특성이 상대적으로 낮다고 보고 되어있다. Type II 다강체는 강자성과 강유전성의 발 현 기원이 모두 특정 스핀 교환 상호작용에서 기인하는 


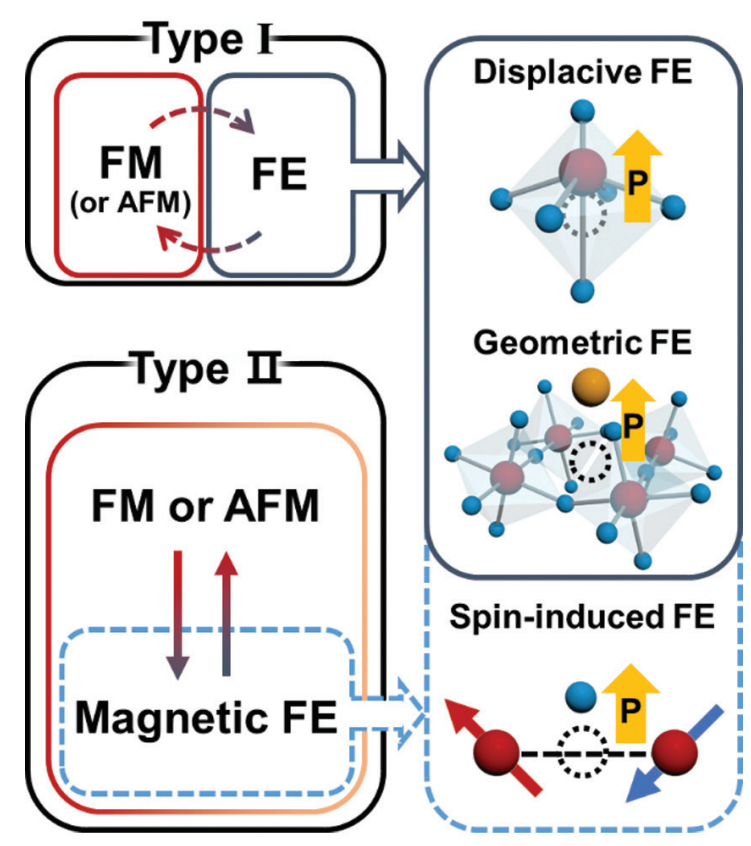

Fig. 2. Schematic illustration accounting for the classification of magnetoelectric multiferroics. Multiferroic oxides are classified into Type | and || depending on the origin of ferroelectricity (FE) rather than that of ferromagnetism (FM) or antiferromagnetism (AFM),

물질군이다. 본 물질군의 경우 강자성과 강유전성의 발 현 기원이 동일하기 때문에, 강한 결속력을 가지며 높 은 자기전기결합 특성을 기대할 수 있다. 또한 많은 물 질이 높은 자성 특징을 나타낸다는 장점도 있다. 하지만 스핀 배열로 인해 발현되는 강유전성은 일반적으로 자 발 분극, 잔류 분극 등의 특성 값이 매우 낮기 때문에 소 자 활용에 제약이 있다는 문제점이 있다. 이러한 분류체 계는 2009년에 Khomskii로부터 제안되었는데 ${ }^{38)}$, 최근 다음과 같은 이유로 현 체계에 대한 모호성을 제기하는 의견이 늘어나는 추세이다; Type I 이나 II 으로 분류하 기 힘든 새로운 물질들이 지속적으로 개발 및 보고되고 있다. ${ }^{22)}$ 또한 최근 들어 강자성과 강유전성이 공존하는 현상보다는 독립적인 두 강성이 서로 강하게 결합하는 현상을 유도하는 것이 화두로 떠오르고 있기 때문에, 두 강성의 결합 방식으로 다강체를 분류 하자는 의견도 제 기되고있다. ${ }^{833)}$ 하지만 Type I, II 로 다강체를 나누는 방식은 가장 보편적으로 통용된다는 점에서, 이러한 분
류 체계를 기반으로 다강체 물질의 연구개발 동향을 기 술하고자 한다.

\subsection{Type | 다강체}

\subsubsection{Displacive ferroelectric perovskite oxides, $\mathrm{ABO}_{3}$}

페로브스카이트 구조 $\left(\mathrm{ABO}_{3}\right)$ 의 변위형 강유전체는 $\mathrm{BaTiO}_{3}$ 의 발견 이래로 꾸준히 화두가 되어왔으며, 다강 체 분야에서는 $\mathrm{B}$ 자리에 강자성 이온이 자리잡고 있는 비스무스 페라이트 $\left(\mathrm{BiFeO}_{3}, \mathrm{BFO}\right)$ 가 가장 대표적이다. 일반적으로 능면체 페로브스카이트 구조를 갖는 $\mathrm{BFO}$ 는 뛰어난 강유전 특성(큐리 온도 $1100 \mathrm{~K}$ )뿐 아니라, 상온 이상에서 반강자성 (닐 온도, Néel temperature 640 $\mathrm{K})$ 을 갖기 때문에 가장 유망한 다강체로 여겨진다. ${ }^{40)}$ $\mathrm{BFO}$ 의 강유전성은 $\mathrm{Bi}$ 의 $6 \mathrm{~s}$ 오비탈과 $\mathrm{O}$ 의 $2 \mathrm{p}$ 오비탈 의 혼성화가 야기하는 변위 때문에, 반강자성은 모든 B 자리를 $\mathrm{Fe}$ 가 차지하며 형성되는 180 도 초교환 상호작 용(superexchange interaction)을 통해 긴 영역 질서 로 스핀이 배열되며 발현된다. ${ }^{41)}$ 이러한 물질과 관련하 여 우선 주목해야할 연구성과로는 2003년에 에피택시 얼(epitaxial)로 쌓아 올린 $\mathrm{BFO}$ 박막에서 보고된 상온 자기전기결합 다강성을 꼽을 수 있다. ${ }^{24)}$ (001) 방향의 $\mathrm{SrTiO}_{3}$ 기판 위에 에피택시얼 성장한 $\mathrm{BFO}$ 박막은 기존 벌크와 같은 능면체 구조가 아니라 단사정계 구조를 가 진 형태로 합성되었다. 이러한 구조 변화로 인해, 보다 더 뛰어난 강유전 특성(자발 분극 $60 \mu \mathrm{C} / \mathrm{cm}^{2}$ )을 보일 뿐 아니라, $\mathrm{Fe}$ 자기 스핀이 기울어져 배열됨에 따라 약 간의 순 자기 모멘트가 생성되는 약한 강자성(포화 자화 값 $150 \mathrm{emu} / \mathrm{cm}^{3}$ ) 또한 측정되었다 (Fig. 3). 또한 당 시에는 외부 자기장을 가해주어 전압의 변화를 관찰하 는 정 자기전기결합 효과만 검증하였지만, 이후 상온에 서 외부 전기장을 가해주어 자화 방향을 제어할 수 있다 는 사실도 실험적으로 직/간접적으로 검증되었다. ${ }^{39,42,43)}$ 이러한 자기전기결합 현상의 메커니즘을 밝히기 위한 연구도 많이 진행되었는데, 그 중 가장 많이 거론되는 것은 지알로신스키-모리야 상호작용이다(스핀과 오비 탈의 결합 작용 방향에 따라 정/역 지알로신스키-모리 
(a)

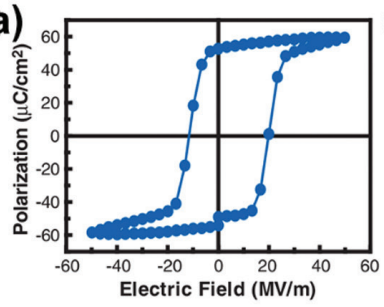

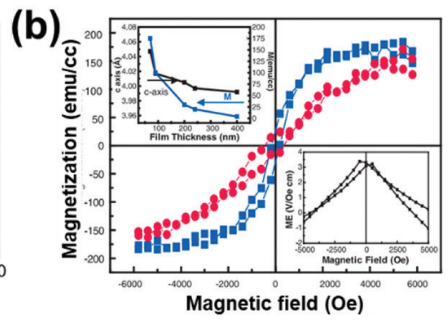

Fig. 3. (a), (b) Ferroelectric and magnetic hysteresis loops of epitaxial $\mathrm{BiFeO}_{3}$ thin film measured at room temperature. Magnetic-field-dependent magnetoelectric coupling is indicated as an inset in (b). (c) Ferroelectric spontaneous polarization, piezoelectric coefficient, and caxis lattice constant depending on the film thickness. Reproduced from Wang et al. under the permission of AAAS Publishing. ${ }^{24)}$

야 상호작용으로 구별되지만, 본 논문에서는 통용하여 작성되었다) ${ }^{44-47)}$ 일반적으로 평행/반평행한 스핀의 배 열과는 달리, 스핀들이 일정한 질서를 가지며 기울어져 배열(스핀 기울어짐, spin canting) 되어있다면 반대칭 (antisymmetric) 교환 상호작용이 작용한다. 반대칭 교 환 상호작용이 작용하는 스핀 배열 상태에서는 외부 자 기장에 따라 스핀과 연관된 오비탈이 영향을 받아 변위 가 발생하며 강유전 분극을 야기할 수 있다. ${ }^{46,48)}$ 반대로 외부 전기장에 따라 강유전 변위가 일어나면서 스핀 기 울어짐이 제어될 수 있는데, 이를 지알로신스키-모리야 상호작용이라 한다. 때문에 지알로신스키-모리야 상호 작용을 통한 강유전 분극의 크기는 중간 매개체를 기준 으로 한 스핀 간 각도와 스핀 모멘트 크기에 영향을 받 는다. 또한 이 상호작용은 자기 스핀과 오비탈이 결합되 어 나타나는 현상으로 해석되며, 다강체 산화물에서 자 기전기결합을 설명할 때 가장 많은 비중을 차지하는 메 커니즘이다. 이를 바탕으로 2014년에 자기전기결합 효 과를 활용한 로직 소자를 설계하여 실험적으로 가능성 을 제시하기도 하였는데, 이는 추후 좀 더 자세히 기술 할 예정이다. ${ }^{49)}$

에피택시얼 성장한 $\mathrm{BFO}$ 박막 기반의 획기적인 연구 들은 페로브스카이트 구조 기반의 다양한 조성 연구가 이루어질 수 있는 기폭제가 되었다. ${ }^{50-54)}$ 우선 무연 변위 형 강유전체의 경우, $\mathrm{BFO}$ 에 가장 널리 쓰이는 강유전체 중 하나인 $\mathrm{BaTiO}_{3}(\mathrm{BTO})$ 를 섞어 합성한 $\mathrm{BFO}-\mathrm{BTO}$ 시 스템이 대표적인 물질 중 하나이다. ${ }^{55,56)} \mathrm{BTO}$ 의 비율을
제어하면 뛰어난 강유전성(자발 분극 $40 \mu \mathrm{C} / \mathrm{cm}^{2}$ )을 보 일 뿐 아니라, 누설전류 및 이차상 생성 등의 기존 $\mathrm{BFO}$ 가 지닌 문제점들이 해결 가능하다. 또한 스핀 기울어짐 이 심화되면서 약한 강자성 모멘트가 개선되는 등의 현 상이 관측되었다는 점에서 주목할 만 하다. 이 외에도, $\mathrm{BFO}, \mathrm{BTO}, \mathrm{Bi}_{1 / 2} \mathrm{Na}_{1 / 2} \mathrm{TiO}_{3}(\mathrm{BNT}), \mathrm{K}_{1 / 2} \mathrm{Na}_{1 / 2} \mathrm{O}_{3}(\mathrm{KNN})$ 등 전형적인 무연 변위형 강유전체를 기반으로 $\mathrm{Mn}, \mathrm{Cr}$, $\mathrm{Nd}, \mathrm{Sm}$ 등 다양한 전이금속과 희토류를 도핑/치환하는 많은 연구 결과들도 보고 되고있다. ${ }^{50,57-63)}$

단일상 다강체로 연구되고 있는 유연 변위형 강 유전체는 이중 페로브스카이트(double perovskite, $\left.\mathrm{AB}^{\prime} \mathrm{B}^{\prime} \mathrm{O}_{3}\right)$ 구조를 가지는 $\mathrm{Pb}\left(\mathrm{Fe}_{1 / 2} \mathrm{Nb}_{1 / 2}\right) \mathrm{O}_{3}(\mathrm{PFN})$, $\mathrm{Pb}\left(\mathrm{Fe}_{1 / 2} \mathrm{Ta}_{1 / 2}\right) \mathrm{O}_{3}(\mathrm{PFT}), \mathrm{Pb}\left(\mathrm{Fe}_{2 / 3} \mathrm{~W}_{1 / 3}\right) \mathrm{O}_{3}(\mathrm{PFW})$ 등이 대 표적이다. ${ }^{9)}$ 이러한 물질군은 다강성이 발현되는 기원 이 $\mathrm{BFO}$ 와 유사하기 때문에, 상당히 높은 강성 전이온 도를 나타낸다. 예를 들어, $\mathrm{PFN}$ 의 큐리 온도와 닐 온 도는 $380,150 \mathrm{~K}$ 이며, PFW의 큐리 온도와 닐 온도는 $180,380 \mathrm{~K}$ 이다. 여기서 $\mathrm{PFW}$ 와 일부 물질들의 경우 닐 온도 이상에서 상당한 보자력과 포화된 자기이력 곡 선이 나타나기도 하는데, 이는 스핀 글래스(spin glass) 효과에 기인한다고 알려져 있다. ${ }^{64)}$ 비슷한 현상이 이전 강유전체 연구에서 보고되어 완화형 강유전체(relaxor ferroelectrics)로 명명되어 있기 때문에, 해당 물질군은 완화형 다강체(relaxor-type multiferroics)로 분류되 곤 한다. ${ }^{65,66)}$

자기 스핀을 갖는 산화물의 자기 거동은 대부분 초교 
환 상호작용으로 설명이 가능하다. ${ }^{67-69)}$ 초교환 상호작 용은 두개의 스핀이 $\mathrm{O}$ 와 같은 중간 매개체를 거쳐서 상 호작용하는 현상을 일컬으며, 굿이너프-카나모리 규칙 (Goodenough-Kanamori rule)은 이러한 초교환 상호 작용에서 오비탈 결합 방식에 따라 달라지는 자기 스핀 배열을 설명하는 규칙이다. ${ }^{70,71)}$ 이 규칙은 매개체를 중 심으로 두 자기 스핀이 180 도로 상호작용 하고 있으면 반강자성을 나타내는 반평행 배열을 이루고, 90 도로 상 호작용한다면 강자성을 나타내는 평행한 배열을 이룬다 는 것을 명시하고 있다. 예를 들어, $\mathrm{BFO}$ 의 경우는 자기 스핀을 가지는 $\mathrm{Fe}$ 가 B 자리에만 존재하기 때문에 180 도 초교환 상호작용만 가능하며, 이 때문에 $\mathrm{BFO}$ 의 자기 거동은 반강자성에 국한된다. $\mathrm{BFO}$ 뿐 아니라 대부분의 페로브스카이트 혹은 이중 페로브스카이트 구조의 다강 체는 180 도 초교환 상호작용으로 인해 반강자성이 강제 된다. 이러한 제약을 극복하기 위해서는 A 자리에 자기 스핀을 가지는 이온을 도입하여 90도 초교환 상호작용 을 유도해야하나, 이러한 시도는 골드슈미트 공차 계수 (Goldschmidt tolerance factor)로 인해 무산될 수 밖 에 없었다; 골드슈미트 공차 계수란 페로브스카이트 구 조에서 각 자리에 존재하는 이온 크기를 고려하여 결정 구조의 왜곡 정도를 판단하는 지표로써, 전이금속이 $\mathrm{A}$ 자리에 들어가게 된다면 상이 불안정해진다는 것을 암 시하고 있다. 이로 인해 페로브스카이트 다강체에서 보 편적인 자성 산화물 정도의 강자성을 이끌어내기 위한 시도들은 크게 정체되어 있는 실정이다.

\subsubsection{Aurivillius oxides, $\left(\mathrm{Bi}_{2} \mathrm{O}_{2}\right)\left(\mathrm{A}_{n-1} \mathrm{~B}_{\mathrm{n}} \mathrm{O}_{3 n+1}\right)$}

오리빌리어스(Aurivillius) 구조는 페로브스카이 트 구조 사이사이에 $\mathrm{Bi}_{2} \mathrm{O}_{2}$ 층을 내포하며, 이러한 $\mathrm{Bi}_{2} \mathrm{O}_{2}$ 층의 개수에 따라 세부적으로 구별되는 층상 구 조의 물질군이다. ${ }^{72-74)}$ 대표적인 오리빌리어스 물질 로 $\mathrm{Bi}_{3.25} \mathrm{La}_{0.75} \mathrm{Ti}_{3} \mathrm{O}_{12}$ (BLT)을 꼽을 수 있다. BLT는 뛰 어난 유전 분극 $\left(\sim 25 \mu \mathrm{C} / \mathrm{m}^{2}\right)$, 큐리 온도( $\left.950 \mathrm{~K}\right)$, 피 로 안정성(fatigue) 등을 나타내는 기하학적 강유전성 을 띠지만, 자기 스핀을 갖는 이온의 부재로 인해 반자 성 또는 상자성을 갖는다. ${ }^{75,76)}$ 이러한 자성과 강유전성
은 상당수의 오리빌리어스 물질에 통용되기 때문에, 전 이금속을 고용함으로써 (반)강자성을 유도하여 새로운 다강체를 개발하려는 움직임이 이었다. 1990년대부터 2000 년대 후반까지 진행된 초기 시도는 $\mathrm{Bi}_{7} \mathrm{Fe}_{3} \mathrm{Ti}_{3} \mathrm{O}_{21}$, $\mathrm{Bi}_{8} \mathrm{Fe}_{4} \mathrm{Ti}_{3} \mathrm{O}_{24}, \mathrm{Bi}_{7} \mathrm{Mn}_{6} \mathrm{Ti}_{6} \mathrm{O}_{21}, \mathrm{Bi}_{5} \mathrm{FeTi}_{3} \mathrm{O}_{15}$ 등 단일 전이 금속을 $\mathrm{Ti}$ 와 치환하여 (반)강자성 성질을 유도하고자 하 는 것이었지만, 상자성에 가까운 자기 이력 곡선 형태에 매우 낮은 자성을 갖는 반강자성을 유도하는 것에 그쳤 다. ${ }^{77-82)}$ 또한 높은 누설전류로 인하여 일반적인 강유전 이력 곡선을 제시하지 못하였고, 강유전 큐리 온도도 급 격하게 낮아지는 경향을 보였기 때문에 큰 관심을 끌지 못하였다.

오리빌리어스 구조의 다강체가 관심을 끌 기 시작한 시기는 전이금속이 다종으로 고용된 $\mathrm{Bi}_{6} \mathrm{Ti}_{2.8} \mathrm{Fe}_{1.52} \mathrm{Mn}_{0.68} \mathrm{O}_{18}$ 과 $\mathrm{Bi}_{4.25} \mathrm{La}_{0.75} \mathrm{Ti}_{3} \mathrm{Fe}_{0.5} \mathrm{Co}_{0.5} \mathrm{O}_{15}$ 같은 조성이 보고된 이후이다. ${ }^{83,84)}$ 특히 $\mathrm{Bi}_{4.25} \mathrm{La}_{0.75} \mathrm{Ti}_{3} \mathrm{Fe}_{0.5} \mathrm{Co}_{0.5} \mathrm{O}_{15}$ 조성에서는 상온에서 2500 $\mathrm{Oe}$ 이하의 낮은 외부 자기장으로도 비교적 상당한 포 화 자화값 $(0.8 \mathrm{emu} / \mathrm{g})$ 을 갖는 강자성 이력 곡선뿐 아 니라, 자기장을 통해 강유전 도메인의 제어가 가능하다 는 것이 실험적으로 검증되었다. 강자성이 유도된 원 인은 서로 다른 자기 모멘트를 지닌 스핀들의 배열 때 문이라고 논의되었다. 즉, 서로 다른 종류의 전이금속 이 고용되어 180도 초교환 상호작용을 한다면, 반평행 하게 배열되어있음에도 불구하고 자기 모멘트가 완벽 하게 상쇄되지 않기 때문에, 순 자기 모멘트가 생성되 어 강자성 특성을 나타내는 것이다. 이러한 자기 스핀 의 배열을 고려하여, 측정된 자기전기결합 효과는 페로 브스카이트와 동일하게 지알로신스키-모리야 상호작용 에서 기인한다고 여겨진다. 비록 높은 누설전류로 인하 여 강유전성을 명확하게 검증하지 못했지만, 해당 연구 는 이전 결과들과 비교하였을 때 유의미한 진전을 보였 다고 여겨진다. 이후 $\mathrm{Bi}_{4} \mathrm{ReTi}_{3} \mathrm{Fe}_{0.7} \mathrm{Co}_{0.3} \mathrm{O}_{15}(\mathrm{Re}=\mathrm{La}$, $\mathrm{Nd}, \mathrm{Ho}), \mathrm{Bi}_{4} \mathrm{LaFeTi}_{3-2 \mathrm{x}}\left(\mathrm{W}_{\mathrm{y}} \mathrm{CO}_{2 \mathrm{y}}\right)_{\mathrm{x}} \mathrm{O}_{15}$ 등 유사한 조성 실 험들이 많이 보고되었다. ${ }^{85-87)}$ 그중 가장 뛰어난 다강성 을 보이는 물질 중 하나로 $\mathrm{Bi}_{3.25} \mathrm{La}_{0.75} \mathrm{Ti}_{2.5} \mathrm{Nb}_{0.25}$ ( $\mathrm{Fe}_{0.5} \mathrm{Co}$ $0.5)_{0.25} \mathrm{O}_{12}$ 를 꼽을 수 있다. ${ }^{28)} \mathrm{Bi}_{3.25} \mathrm{La}_{0.75} \mathrm{Ti}_{3} \mathrm{O}_{12}$ 조성의 $\mathrm{Ti}$ 
를 $\mathrm{Nb}_{0.25}\left(\mathrm{Fe}_{0.5} \mathrm{Co}_{0.5}\right)$ 로 치환한 시스템 중 한 조성으로, 기존 $\mathrm{Ti}$ 를 전이금속들로 치환할 때 필연적으로 발생하는 전하 수 불균형을 해결하고자 $\mathrm{Nb}$ 와 함께 치환한 것으로 판단된다. ${ }^{84)}$ 이러한 조성 설계를 통해, 상온에서 잘 포 화된 자기 이력 곡선(포화 자화값 $0.5 \mathrm{emu} / \mathrm{g}$, 큐리 온 도 $380 \mathrm{~K})$ 을 얻었을 뿐 아니라, 낮은 누설 전류는 물 론 뛰어난 강유전성(포화 분극 $18 \mu \mathrm{C} / \mathrm{cm}^{2}$, 큐리 온도 $\sim 555 \mathrm{~K})$ 또한 확보하였다. 게다가 $\sim 0.5 \mathrm{mV} / \mathrm{cm} \cdot \mathrm{Oe}$ 에 달하는 자기전기결합 상수도 측정되었는데, 상온에 서 강자성과 강유전성이 결합된 단일상 다강체가 매우 희귀하다는 것을 고려한다면 주목할만한 결과라 판단 된다.

전술한 바와 같이, 산화물에서의 강자성은 90 도 초교 환 상호작용에서 기인하고, 반대칭 교환상호작용으로 기대할 수 있는 자화값은 한정적이다. 이러한 사실을 상 기한다면 오리빌리어스 구조에서 전이금속의 다종 치환 을 통해 얻어진 강자성은 그 한계가 존재할 것이라 예상 되며, 새로운 돌파구가 필요할 것으로 판단된다. 또한 자기전기결합 현상이 지알로신스키-모리야 상호작용에 서 기원하기 때문에 상대적으로 낮은 외부 자기장 혹은 전기장으로 제어가 가능하다는 장점이 있지만, 스핀이 격자, 혹은 전하와 결합되었을 때 얻을 수 있는 결합 상 수보다는 제한될 것이라 예상된다. 상온 자기전기결합 다강성이 단일상 오리빌리어스 구조 물질에서 검증되었 다는 사실은 충분히 고무적이지만, 페로브스카이트 물 질군과 마찬가지로 90 도 초교환 상호작용을 통한 강자 성과 강하게 결합된 자기전기 효과를 유도하기 위한 연 구가 추가적으로 진행될 필요가 있다.

\subsubsection{Hexagonal rare-earth manganite, $\mathrm{h}-\mathrm{RMnO}_{3}(\mathrm{R}=$ rare earth)}

육방정 망가네이트 물질은 희토류의 이온 사이즈 등 의 요인들로 인해 Type I 다강체인 육방정 구조를 가 질 수 도 있고, 후에 서술될 Type II 다강체의 사방정 구조를 형성할 수도 있다. 육방정 망가네이트 구조의 $\mathrm{h}-\mathrm{YMnO}_{3}(\mathrm{YMO})$ 는 이 물질군에서 처음으로 유의미한 자기전기 다강성이 검증된 대표적인 물질로 알려져 있
다. Type I 다강체인 육방정 망가네이트의 경우, 주로 강유전 큐리 온도가 $1000 \mathrm{~K}$ 근방이고 반강자성 닐 온도 는 $100 \mathrm{~K}$ 근방에서 형성되어 있는데, $\mathrm{YMO}$ 도 이와 비슷 한 강성 전이온도를 나타낸다(큐리 온도 $900 \mathrm{~K}$, 닐 온 도 $65 \mathrm{~K}){ }^{88)}$ 이 물질군의 $\mathrm{Mn}$ 이온들은 $\mathrm{O}$ 를 매개체로 120 도를 이루는 삼각 결합을 통해 상호작용하고 있는 데, 이때 발생하는 스핀 쩔쩔맴(frustration) 현상으로 인해 약한(weak) 혹은 기운(canted) 반강자성 성질이 발현되어 약간의 순 자기 모멘트가 생성된다고 알려져 있다. 강유전성의 발현 기원에 대한 논의는 아직 진행중 이나, 주를 이루는 의견은 $\mathrm{P} 6_{3} \mathrm{~cm}$ (강유전성)에서 $\mathrm{P} 6_{3} /$ $\mathrm{mmc}$ (상유전성)으로 구조적 전이가 일어나 강유전 특성 이 유발된다는 것이다(기하학적 강유전체). ${ }^{89,90)}$ 즉, 전기 장과 같은 외부에서 작용하는 힘으로 인해 쌍뿔 구조의 $\mathrm{MnO}_{5}$ 산소 케이지가 뒤틀리며 구조 전이가 발생하며, 이때 R 자리 이온의 변위로 인한 강유전 분극(포화 분극 $\left.\sim 6 \mu \mathrm{C} / \mathrm{cm}^{2}\right)$ 을 생성하는 것이다. 이와 같이 반강자성과 강유전성이 공통적으로 $\mathrm{Mn}$ 의 거동과 연관되어 발현되 기 때문에, 이 물질군 기반의 다강체에서는 이론상으로 강한 자기전기결합 상수가 예상되었다. 실제로 $\mathrm{YMO}$ 의 자기전기결합 특성은 상온에서도 상당한 값으로 보고되 었으며(자기전기결합 상수 $\sim 2 \mathrm{mV} / \mathrm{cm} ・ \mathrm{Oe}$ ), 동일한 물질군의 다른 물질들에서도 준수한 특성값인 것으로 나타난다. 이에 많은 기대를 받으며 현재까지도 메커니 즘 분석, 특성 개선 등을 위한 연구가 지속되고있으나, 자성 전이 온도와 모멘트가 낮다는 점은 여전히 개선이 필요한 문제점으로 남아있다. 이러한 문제점은 해당 물 질군 역시 반평행하게 배열 되어있는 $\mathrm{Mn}$ 스핀이 기울어 지며 발현되는 기울어진 반강자성을 갖기 때문이므로, 연구 진전에 난항을 겪고있는 실정이다.

\subsubsection{Rhombohedral rare-earth ferrite, $\mathrm{RFe}_{2} \mathrm{O}_{4}(\mathrm{R}=$ rare earth)}

능면체 페라이트 물질의 경우, 삼각형 격자 (triangular lattice)층의 동일한 자리에 $\mathrm{Fe}$ 이온들이 +2 가와 +3 가로 혼재되어 분포하고 있기 때문에, 평균적 으로 +2.5 가를 나타내는 것으로 잘 알려져 있다. 이러 
한 독특한 원자 배열로 인해 전하의 쩔쩔맴 상태가 유발 될 수 있고, 이는 전하 정렬(charge ordering)로 인해 발현되는 전자 강유전체(electronic ferroelectrics)가 될 수 있음을 가리킨다. 대표적인 능면체 페라이트 물질 은 $\mathrm{LuFe}_{2} \mathrm{O}_{4}$ 로, 2005 년에 단결정에서 주목할만한 강유 전성이 보고되면서 주목을 받기 시작했다; $\mathrm{LuFe}_{2} \mathrm{O}_{4}$ 의 큐리 온도는 $\sim 330 \mathrm{~K}$ 이며 자발 분극은 $\sim 20 \mu \mathrm{C} / \mathrm{cm}^{2}$ 이 다. ${ }^{91-93)} \mathrm{LuFe}_{2} \mathrm{O}_{4}$ 는 220-250 K 범위에서 긴 범위 스핀 정렬을 보이는 반강자성을 가지고, 그 이하에서는 정렬 상태가 짧아지면서 생성되는 스핀 유리(glass)계로 인 한 약한 강자성과 함께 반강자성이 공존하는 형태인 것 으로 알려져 있다. $\mathrm{LuFe}_{2} \mathrm{O}_{4}$ 와 관련된 연구는 최근 강유 전성에대한 의문이 제기되었을 뿐만 아니라, 온도에 따 른 자성/강유전성 상전이, 스핀/전하 정렬 상태 등의 관 련 메커니즘을 밝히기 위한 연구 진척이 더뎌지며 점차 관심이 식어가고 있었다. 하지만 $\mathrm{LuFe}_{2} \mathrm{O}_{4}$ 와 육방정 페 라이트 물질인 $\mathrm{h}-\mathrm{LuFeO}_{3}$ 를 원자층 증착(ALD, atomic layer deposition) 방식을 통해 $\left(\mathrm{LuFeO}_{3}\right)_{\mathrm{m}} /\left(\mathrm{LuFe}_{2} \mathrm{O}_{4}\right)_{1}$ $(1 \leq \mathrm{m} \leq 10)$ 초격자 시스템으로 합성하여 뛰어난 자기 전기결합 다강성을 보여준 이후로 다시 주목받기 시 작하였다. ${ }^{94,95)} \mathrm{LuFe}_{2} \mathrm{O}_{4}$ 는 전술한 바와 같이 상대적으 로 높은 닐 온도를 가지며 스핀 쩔쩔맴 현상 제어를 통 해 순 자기 모멘트의 증대가 가능하다. $\mathrm{h}-\mathrm{LuFeO}_{3}$ 는 언 급된 육방정 망가네이트 물질군의 특징처럼, 뛰어난 기 하학적 강유전성을 나타내는 것으로 알려져 있다 이러 한 두 조성이 초격차 형태로 합성되며 서로 상호보완적 인 형태를 취하는 것이 확인되었으며, 특히 $\left(\mathrm{LuFeO}_{3}\right)_{9} /$ $\left.\left(\mathrm{LuFe}_{2} \mathrm{O}_{4}\right)_{1}\right)$ 조성의 강자성과 강유전 큐리 온도는 각각 $281,1020 \mathrm{~K}$ 로 주목할만한 성취를 이룬 것이 확인되었 다. 추후 $\mathrm{Fe}^{2+}$ 와 $\mathrm{Fe}^{3+}$ 간의 전하 전달 현상으로 인해 자 기전기결합 현상이 발현된다는 것이 이론적/실험적으로 검증되었으나, 단일상이 아닌 두 물질의 복합체 형태라 는 의견이 주를 이루고 있어서 가치가 일부 희석되었다.

\subsection{Type || 다강체}

\subsubsection{Orthorhombic rare-earth manganite, o- $\mathrm{RMnO}_{3}(\mathrm{R}=$ rare earth)}

사방정 망가네이트 물질군인 $\mathrm{TbMnO}_{3}(\mathrm{TMO})$ 는 2003 년에 물리적 관점으로 상당히 의미 있는 자기전기 다강 성이 보고된 이후로, Type II 다강체 연구에 많은 영 향을 끼친 대표적인 물질로 자리매김하고 있다. ${ }^{25,96,97)}$ $\mathrm{TMO}$ 의 자기 스핀은 상온에서 무질서하게 배열되어 상 자성을 띠고, $41 \mathrm{~K}$ 아래로 온도가 내려가면 일반적인 반 강자성 스핀 배열을 나타낸다. 온도가 $28 \mathrm{~K}$ 밑으로 더 떨어지면, 사이클로이트 형태로 반전 대칭이 깨지는 반 강자성 스핀 배열이 된다. 여기서 강유전성은 전적으로 스핀 교환 상호작용에서 기인하기 때문에, 강유전 큐리 온도는 지알로신스키-모리야 상호작용을 통해 강유전 분극을 유도할 수 있는 비대칭 스핀 배열과 연관된 전이 온도인 $28 \mathrm{~K}$ 이다. 이는 단결정을 활용한 온도에 따른 강유전 분극 측정 실험을 통해 검증되었으며, 분극 값 은 $28 \mathrm{~K}$ 부터 온도가 떨어짐에 따라 증가하여 종래에는 $0.08 \mu \mathrm{C} / \mathrm{cm}^{2}(\sim 10 \mathrm{~K})$ 근방까지 상승한다. 이후 $\mathrm{TMO}$ 에서 자기전기결합 효과가 실험적/이론적으로 검증되었 으나, 여전히 반강자성 닐 온도 및 강유전성 큐리 온도, 강유전 자발 분극 등이 매우 낮기 때문에 소자에 활용하 기에 지난한 실정이다. 이러한 문제점들을 개선하기 위 해 조성 치환 등의 많은 연구가 진행되었고, 그중 하나 인 외부 압력을 통한 다강성 향상에 관한 연구를 소개하 고자 한다. ${ }^{98)}$ 상압에서의 $\mathrm{TMO}$ 는 $28 \mathrm{~K}$ 이하에서 소용 돌이 치는 형태의 스핀 배열을 가지는데, $4.5 \mathrm{GPa}$ 이상 으로 압력을 가해줄 경우 $\mathrm{E}$-type 반강자성 배열을 가지 게 된다. E-type 반강자성 배열은 자기 스핀이 위-위아래-아래 방향으로 정렬 되어있는 형태로, 스핀 간 인 력-척력이 작용하여 원자 변위를 야기하는 대칭 교환 변형(exchange striction)을 통해 상대적으로 큰 강유 전 분극을 생성할 수 있는 구조이다. 실제로 측정된 강 유전 자발분극 값은 $\sim 0.2 \mu \mathrm{C} / \mathrm{cm}^{2}(\sim 10 \mathrm{~K})$ 으로 지알로 신스키-모리야 상호작용으로 인한 자발 분극값보다는 크게 측정되었다. 하지만 이러한 값은 이론적으로 예상 
되는 수 $\mu \mathrm{C} / \mathrm{cm}^{2}$ 정도보다는 매우 작은 값으로, 이론값 을 실험적으로 구현하기 위한 노력은 여전히 지속되고 있다. 이 외에도 $\mathrm{TbMn}_{2} \mathrm{O}_{5}$ 등 화학식이 조금 다른 사방 정 망가네이트 물질군인 $\mathrm{RMn}_{2} \mathrm{O}_{5}$ 에서도 자기전기 다강 성에 대한 연구 역시 활발히 진행되고 있다.

\subsubsection{Y/Z-type hexaferrite, (Ba, $\mathrm{Sr})_{2} \mathrm{Me}_{2} \mathrm{Fe}_{12} \mathrm{O}_{22}$ and (Ba, $\mathrm{Sr})_{3} \mathrm{Me}_{2} \mathrm{Fe}_{24} \mathrm{O}_{41}(\mathrm{Me}=$ divalent metal)}

헥사페라이트 구조는 3 가지 층 $\left(\mathrm{S} ; \mathrm{Me}^{2+} \mathrm{Fe}_{4} \mathrm{O}_{8}\right.$, $\left.\left.\mathrm{R} ;\left[(\mathrm{Ba}, \mathrm{Sr}) \mathrm{Fe}_{6} \mathrm{O}_{11}\right]^{2-}, \mathrm{T} ;(\mathrm{Ba}, \mathrm{Sr})_{2} \mathrm{Fe}_{8} \mathrm{O}_{14}\right]\right)$ 으로 구성되 어있고, 이러한 층의 조합에 따라 $\mathrm{M}, \mathrm{W}, \mathrm{X}, \mathrm{Y}, \mathrm{Z}, \mathrm{U}$ type 으로 나뉘어 진다. ${ }^{99)}$ 이 중, Y-type과 Z-type 헥사페 라이트에서 뛰어난 자기전기결합 현상이 보고되고 있 으며, 각각의 화학식은 $(\mathrm{Ba}, \mathrm{Sr})_{3} \mathrm{Me}_{2} \mathrm{Fe}_{24} \mathrm{O}_{41}$ 과 $(\mathrm{Ba}$, $\mathrm{Sr})_{2} \mathrm{Me}_{2} \mathrm{Fe}_{12} \mathrm{O}_{22}$ ( $\mathrm{Me}=2$ 가의 금속) 이다; $\mathrm{M}$-type 헥 사페라이트 에서도 자기전기 다강성이 보고된 바 있으 나, 아직 명확히 검증되지 않았다. 헥사페라이트 구조에 서의 자기전기결합 현상 발현 기원은 지알로신스키-모 리야 상호작용으로 대부분 동일하지만, 나사, 원뿔 형 태 등 다양한 스핀 배열을 기준으로 세분화되고 있다. 2000년대 초부터 Y-type헥사페라이트 구조를 갖는 $\mathrm{Ba}_{2} \mathrm{Mg}_{2} \mathrm{Fe}_{12} \mathrm{O}_{22}, \mathrm{Ba}_{0.5} \mathrm{Sr}_{1.5} \mathrm{Zn}_{2} \mathrm{Fe}_{12} \mathrm{O}_{22}, \mathrm{Ba}_{0.5} \mathrm{Sr}_{1.5} \mathrm{Zn}_{2}\left(\mathrm{Fe}_{1-}\right.$ $\left.{ }_{x} \mathrm{Al}_{\mathrm{x}}\right)_{12} \mathrm{O}_{22}$ 등의 물질에서 의미 있는 자기전기결합 현상 이 관측되었다. ${ }^{26,102)}$ 이 시기에 보고된 다강체들의 경 우, 외부 자기장에 따라 점진적으로 변화하는 스핀이 기 울어진 배열 형태로 인해 다강성이 유도되는 것으로 분 석되어 있는데, 이러한 자기 상전이로는 충분한 강유 전 분극을 유도하지 못하고 있는 실정이었다. 2017년 에 $\mathrm{Ba}_{0.4} \mathrm{Sr}_{1.6} \mathrm{Mg}_{2} \mathrm{Fe}_{12} \mathrm{O}_{22}$ 단결정에서 거대한 자기전기 결합 상수 $(\sim 33,000 \mathrm{ps} / \mathrm{m}, 10 \mathrm{~K})$ 와 강유전 분극(0.02 $\mu \mathrm{C} / \mathrm{cm}^{2}, 10 \mathrm{~K}$ )이 나타나는 현상이 보고되었다 (Fig. 4(a)). ${ }^{100)}$ 측정된 거대 자기전기결합 효과의 원인은 기 존 물질들과 비교하였을 때, 상대적으로 급격하게 변하 는 스핀 구조 변화에 있다. 예를 들어, 기존의 물질이 외 부 자기장에 따라 두겹(two-fold) 스핀 구조에서 부정 합(incommensurate), 네겹(four-fold) 배열을 거쳐 두 겹 스핀 구조로 회귀한다면, $\mathrm{Ba}_{0.4} \mathrm{Sr}_{1,6} \mathrm{Mg}_{2} \mathrm{Fe}_{12} \mathrm{O}_{22}$ 단결
정의 스핀 구조는 두겹에서 의사네겹(quasi four-fold) 만을 거쳐 두겹 스핀 구조로 급격하게 회귀한다. 지알로 신스키-모리야 상호작용을 기반한 스핀 유도 강유전 분 극이 스핀 기울어짐의 정도와 관련되어 있다는 점에서, $\mathrm{Ba}_{0.4} \mathrm{Sr}_{1.6} \mathrm{Mg}_{2} \mathrm{Fe}_{12} \mathrm{O}_{22}$ 단결정의 거대 자기전기결합 효과 는 언급된 스핀 구조의 변화로 충분히 설명 가능하다. 이 외에도 온도 및 자기장 크기에 따른 자기 스핀 구조 의 변화를 제시하는 메커니즘, 향상된 자기전기 다강성 등 다양한 연구가 보고되었으나, 여전히 낮은 온도 영역 (5-30 K)에서 낮은 강유전 분극 $\left(0.01-0.03 \mu \mathrm{C} / \mathrm{cm}^{2}\right)$ 이 유도되는 실정이었다.

Z-type 헥사페라이트는 Y-type과 달리 상온에서 자 기전기결합 특성이 실험적으로 검증된 물질군이다. 이 전부터 강자성 산화물(닐 온도 510, $670 \mathrm{~K}$ )로 잘 알 려져 있었던 $\mathrm{Sr}_{3} \mathrm{Co}_{2} \mathrm{Fe}_{24} \mathrm{O}_{41}$ 은 상온임에도 불구하고 강 유전 분극 $\left(\sim 0.001 \mu \mathrm{C} / \mathrm{cm}^{2}\right)$ 이 유도되는 현상이 2010 년에 보고되며 주목받기 시작했다. ${ }^{101)}$ 측정에 사용된 샘 플이 단결정이 아닌 다결정이라는 점, 낮은 외부 자기 장 $(〈 3000 \mathrm{Oe})$ 에서 강유전 분극이 유도된다는 점 등은 $\mathrm{Sr}_{3} \mathrm{Co}_{2} \mathrm{Fe}_{24} \mathrm{O}_{41}$ 의 차별성을 더 부각시켜준다. 이러한 결 과는 헥사페라이트 물질군에서 지알로신스키-모리야 상호작용을 통해 상온 이상에서 충분한 다강성이 유도 될 수 있다는 가능성을 제시하였다. 이후 2018년에 보고 된 $\mathrm{Sr}_{3} \mathrm{Co}_{2} \mathrm{Fe}_{24} \mathrm{O}_{41}$ 단결정을 통해 향상된 특성값과 함께 자기전기결합 다강체를 활용한 비휘발 메모리의 가능성 이 확인되었다. ${ }^{103)}$ 모든 측정은 상온에서 진행되었으며, 자기장 대비 유전율 변화(4\%), 강유전 분극( $0.002 \mu$ $\left.\mathrm{C} / \mathrm{cm}^{2}\right)$, 자기전기결합 상수 $(15 \mathrm{mV} / \mathrm{cm} \cdot \mathrm{Oe})$ 및 장 대 비 자화값 $(0.25 \mathrm{emu} / \mathrm{g})$ 이 검증되었다 (Fig. 4(b)). 또한 자기전기 다강체를 활용한 고집적/저전력 메모리의 구 현 가능성을 검증하기 위해, 펄스 신호 형태로 값을 측 정하여 제시하였다; $5 \mathrm{kV} / \mathrm{cm}$ 의 전기장 신호를 $20 \mathrm{~ns}$ 이내로 가하여 $1-2 \mathrm{mV} / \mathrm{cm} \cdot$ Oe값을 얻었고, 이는 메 모리 읽기/쓰기 성능을 어느정도 유추할 수 있게 한다. 제시된 실험 값들은 아직 소자 활용에 충분하지는 않지 만 가능성을 보여줬다는 점에서 의의가 있다. 
(a)
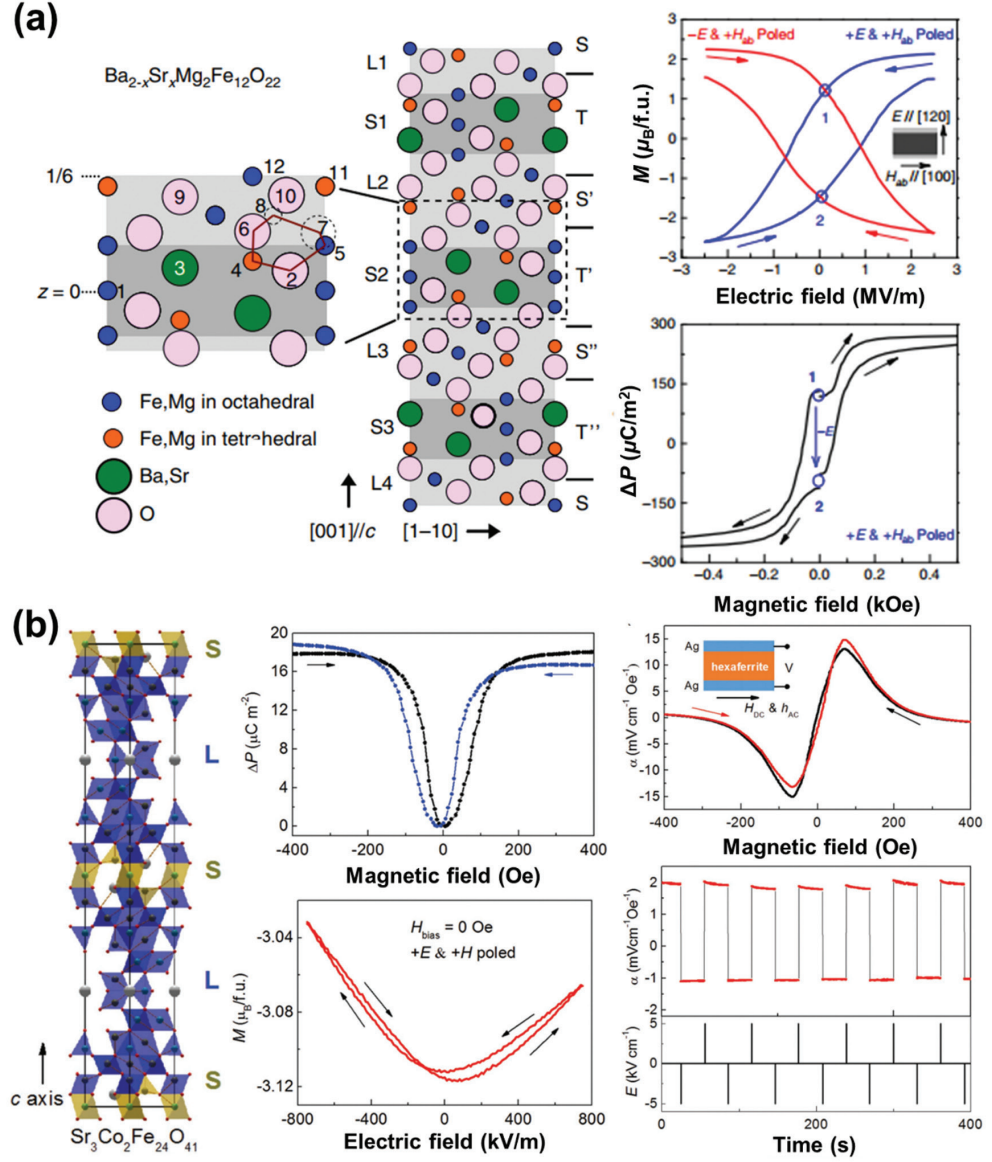

Fig. 4. (a) Schematic illustration of $Y$-type hexaferrite along with both electric and magnetic-field-dependent magnetoelectric coupling of $\mathrm{Ba}_{0.4} \mathrm{Sr}_{1.6} \mathrm{Mg}_{2} \mathrm{Fe}_{12} \mathrm{O}_{22}$ single crystal measured at $10 \mathrm{~K}$. Reproduced from Zhai et al. under the permission of Nature Publishing. ${ }^{100)}$ (b) Schematic illustration of Z-type hexaferrite along with room-temperature magnetoelectric coupling of $\mathrm{Sr}_{3} \mathrm{CO}_{2} \mathrm{Fe}_{24} \mathrm{O}_{41}$ single crystal. Reproduced from Zhai et al. under the permission of Nature Publishing. ${ }^{103)}$

\subsubsection{Spinel oxides, $\mathrm{AB}_{2} \mathrm{O}_{4}$}

스피넬 구조는 $1: 2$ 비율로 원자들이 4면체와 8 면체 를 채우는 형태로 구성되어 있으며, 원자 배열에 따라 정 스피넬 $\left([\mathrm{A}]_{\mathrm{tet}}[\mathrm{B}, \mathrm{B}]_{\mathrm{oct}} \mathrm{O}_{3}\right)$ 또는 역 스피넬 $\left([\mathrm{B}]_{\mathrm{tet}}[\mathrm{A}, \mathrm{B}]\right.$ $\left.{ }_{\mathrm{oct}} \mathrm{O}_{3}\right)$ 구조로 나뉜다. 이러한 차이는 각각의 산소 케이 지에 고용된 전이금속의 종류에 영향을 받는데, 이는 각 이온 사이즈에 따라 선호하는 위치가 달라지기 때문 이다. 원자 배열과 전이금속의 구성에 따라 스피넬 산 화물에서 자성 거동의 제어가 가능하며, 이를 통해 스 핀 유도 강유전 분극의 생성도 가능케한다. 헥사페라이 트의 경우 자기전기결합 현상의 대다수가 지알로신스 키-모리야 상호작용을 통해 발현되지만, 스피넬의 경우
엔 지알로신스키-모리야 상호작용뿐 아니라 교환 변형 과 $\mathrm{p}-\mathrm{d}$ 오비탈 혼성화와 같이 여러 발현 기원이 존재한 다. ${ }^{106)}$ 대표적인 스피넬 다강체중 하나로 정 스피넬 구 조를 갖는 $\mathrm{CoCr}_{2} \mathrm{O}_{4}(\mathrm{CCO})$ 를 꼽을 수 있다. ${ }^{104)} \mathrm{CCO}$ 의 강 자성 큐리 온도는 $93 \mathrm{~K}$ 이나, 특이점 $(\sim 26 \mathrm{~K})$ 이하에서 는 원뿔형 스핀 배열이 나타나기 시작한다. 실험적으로 $26 \mathrm{~K}$ 이하에서 강유전 분극이 점점 증가하는 것이 확인 되었으며, $18 \mathrm{~K}$ 에서 포화 분극이 $\sim 0.0002 \mu \mathrm{C} / \mathrm{cm}^{2}$ 수 준이다 (Fig. 5(a)). CCO 단결정에서 보고된 자기전기 다강성은 강성 전이 온도나 분극 측면에서 그리 뛰어나 지는 않지만, 스피넬 구조에서 지알로신스키-모리야 상 호작용을 통한 강유전성을 명확히 제시하였다는 점에서 
(a)

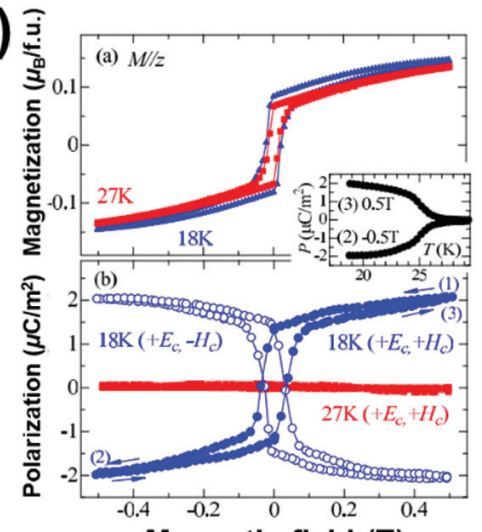

(b)

Magnetic field (T)

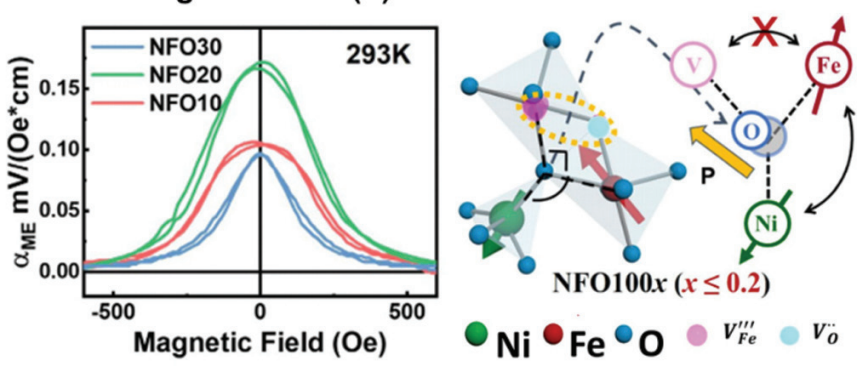

Fig. 5. (a) Magnetic hysteresis loop and magnetic-field-dependent magnetoelectric coupling of $\mathrm{CoCr}_{2} \mathrm{O}_{4}$ single crystal obtained at 18, $27 \mathrm{~K}$ along with schematic illustrations accounting for its magnetic spin arrangement. Reproduced from Yamasaki et al. under the permission of APS Publishing. ${ }^{104)}$ (b) Room-temperature magnetoelectric coupling of defect-engineered $\mathrm{NiFe}_{2} \mathrm{O}_{4}$ under the magnetic field up to 600 Oe and schematic illustration explaining its mechanism. Reproduced from Cho et al. under the permission of Wiley Publishing. ${ }^{105)}$

높게 평가 가능하다. 이 외에도 교환 변형을 통해 다강 성을 나타내는 $\mathrm{CoAl}_{2} \mathrm{O}_{4}$ 등 다양한 정 스피넬 물질군에서 자기전기결합 다강성이 연구되고 있다. ${ }^{107)}$

$\mathrm{NiFe}_{2} \mathrm{O}_{4}(\mathrm{NFO})$ 는 대표적인 역 스피넬 구조의 강자성 산화물이다(포자 자화값 $40 \mathrm{emu} / \mathrm{g}$, 강자성 큐리 온도 $\sim 840 \mathrm{~K})$. 하지만 $98 \mathrm{~K}$ 밑으로 온도가 떨어진다면, 구조가 정방 정계로 전이되어 $\mathrm{Fe}$ 의 d 오비탈과 $\mathrm{O}$ 의 $\mathrm{p}$ 오비탈이 혼성화되어 $\mathrm{Fe}$ 이온의 변위가 발생할 수 있다 는 것이 밝혀졌다. ${ }^{108,109)}$ 이러한 $\mathrm{p}-\mathrm{d}$ 오비탈 혼성화에 따 른 강유전성의 큐리 온도는 $~ 98 \mathrm{~K}$ 이며, 상당한 강유전 분극 $\left(\sim 0.29 \mu \mathrm{C} / \mathrm{cm}^{2}\right)$ 이 실험적으로 검증되었다. 하지만 이러한 분극 값은 밀도범함수 이론(density functional theory, DFT) 계산으로 도출된 값인 $\sim 23 \mu \mathrm{C} / \mathrm{cm}^{2}$ 에 크게 미치지 못하였기에 다른 해석이 제안되기도 한 다. ${ }^{110)}$ 예를 들어, 역 스피넬 구조의 자기 배열이 온도가
낮아지면서 규칙적으로 변하며, 이는 교환 변형을 유도 가능하기 때문에 강유전 분극이 유도된다는 것이다. 하 지만 이 또한 명확하게 현상을 설명하지 못하기 때문에, 제시된 이론적 강유전 분극값과 메커니즘 규명을 위해 지속적으로 연구가 진행되고 있다.

최근 상온에서 결함 제어를 통해 $\mathrm{NFO}$ 의 자기전 기 다강성을 제어한 또다른 연구가 보고되었다 (Fig. $5(\mathrm{~b})) .{ }^{105)} \mathrm{NFO}$ 의 원자 배열은 절반의 $\mathrm{Fe}$ 가 사면체에 자 리잡고, 나머지 $\mathrm{Fe}$ 와 $\mathrm{Ni}$ 이온 전부가 팔면체에 존재하 는 형태이다. 굿이너프-카나모리 규칙에 따라, 각 자리 의 $\mathrm{Fe}$ 스핀들끼리 상쇄가 일어나고 $\mathrm{Ni}$ 의 스핀 모멘트만 남아 강자성 거동을 보인다. 이러한 스핀 구조에서 $\mathrm{Fe}$ 와 $\mathrm{O}$ 의 결함을 인위적으로 생성하여 반전 대칭을 깨트 렸고, 이를 통해 지알로신스키-모리야 상호작용으로 설 명 가능한 자기전기결합 현상을 제어 가능하다는 것이 
밝혀졌다. 상온에서 자기전기결합 상수가 $\sim 0.8 \mathrm{mV} /$ $\mathrm{cm} \cdot \mathrm{Oe}$ 까지 향상되는 것뿐 아니라, 압전감응 힘 현미 경(piezoresponse force microscopy, PFM)을 통해 강 유전성을 실험적으로 검증하였다. 이는 역 스피넬 구 조가 상온에서 중심 대칭인 입방체 구조 임에도 불구하 고, 국부적으로 결함을 유도하여 자기전기결합 다강성 을 유도할 수 있다는 가능성을 제시하였다. 이 외에도 $\mathrm{MnCr}_{2} \mathrm{O}_{4}$ 등 다양한 역 스피넬 물질에서 다강성을 개발 하고 증명해 나아가고 있다. ${ }^{111}$

\subsubsection{Tenorite, $\mathrm{CuO}$}

$\mathrm{CuO}$ 는 단사정계 구조의 이성분계 반강자성 산화물이 다. $\mathrm{CuO}$ 는 지그재그 형태의 자기 스핀 배열을 가지며, 닐 온도는 230 과 $213 \mathrm{~K}$ 두개로 나뉜다; 두 닐 온도 사 이의 범위에서는 나선형 스핀 배열을 갖는 반강자성을, $213 \mathrm{~K}$ 이하에서는 반평행한 스핀 배열을 갖는 일반적인 반강자성을 나타낸다. ${ }^{112)}$ 즉, $213-230 \mathrm{~K}$ 온도 범위 내 에서만 자기 스핀 배열의 대칭이 깨진 부정합 구조를 가 지게 된다. 이는 일반적인 강유전체의 온도에 따른 유전 율 변화 곡선과 같이, 강유전 상전이 온도로 예상되는 $230 \mathrm{~K}$ 에서만 유전율이 급격히 상승하여 최고점을 찍은 뒤 다시 감소하는 형태를 통해 검증 되었다. 이러한 자 기 상평형도를 나타내기 때문에, $\mathrm{CuO}$ 는 두 닐온도 사이 의 좁은 범위에서 스핀 유도 강유전성을 나타낸다(포화 분극 $\left.0.015 \mu \mathrm{C} / \mathrm{cm}^{2}, 220 \mathrm{~K}\right)$. 해당 온도 범위에서의 스 핀 배열은 아직 확실하지 않으나, 파선형이나 나사형 스 핀 배열이 가장 유력하기 때문에 강유전성의 발현 기원 은 일반적인 지알로신스키-모리야 상호작용으로 설명 된다. 비록 다강성을 나타낼 수 있는 온도 범위가 좁지 만, 준수한 다강성과 함께 $\mathrm{CuO}$ 가 이성분계 다강체 산화 물이라는 점은 주목할만하다. 따라서 $\mathrm{CuO}$ 에서 자기전 기 다강성이 발견된 사실은 물리학적인 측면 뿐만 아니 라, 다강체기반의 차세대 소자 구현 측면에서도 매우 흥 미롭고 의미 있는 발견이라 여겨진다.

\section{3. 자기전기 다강성을 활용한 소자 연구개발 동향}

전술한 바와 같이, 자기전기 다강체는 강자성과 강유 전성 뿐만 아니라, 두 강성이 결합되어 상호작용하는 현 상을 단일상에서 구현 가능한 물질이다. 이러한 독특한 현상을 활용한다면, 기존 물질로는 구현하기 힘든 다양 한 소자 개발이 가능할 것이라 거론되고있다. 대표적인 소자 중 하나로, 현재 가장 첨예하게 대두되고 있는 분 야 중 하나인 데이터 저장 및 처리 소자가 있다. ${ }^{15,113)}$ 차 세대 메모리는 주로 비휘발성, 고집적도, 저전력, 저비 용 등의 요건을 만족시키기 위한 방향으로 연구가 진 행되고 있다. 이미 강자성이나 강유전성을 활용한 비 휘발성 메모리인 MRAM(magnetic random access memory), FeRAM(ferroelectric random access memory)이 연구되고 있으며, 많은 성과를 이루어 일부 상용화된 상태이다. 자기전기 다강체는 전기 신호를 주 어 자기 분극 뿐만 아니라 유전 분극 또한 제어 가능하 다는 점에 착안하여(자기 신호를 주어 특성의 제어도 가 능하지만, 소비 전력이 더 낮은 전압 신호가 더 각광받 고 있다), 다중 정보 처리가 가능한 MERAM 구현을 위 한 여러 형태가 제안되었다 (Fig. 6(a)). 전극/다강체/전 극 형태의 터널 접합 구조를 기본적으로 갖는 MERAM 은 자기 터널 효과와 강유전 자발 분극에 의한 다중 정 보 처리 및 저장이 가능하여 소자의 고집적화가 가능할 뿐 아니라, 빠른 정보처리 속도, 낮은 소비 전력도 구현 가능할 것으로 기대되고 있다. 실험적으로 검증된 대표 적인 자기전기 터널 접합 구조를 가지는 메모리로, 자기 전기 스핀-오빗(magnetoelectric spin-orbit, MESO) 소자가 있다. ${ }^{49)} \mathrm{MESO}$ 소자는 반강자성/강유전성을 지 니는 다강체(즉, $\mathrm{BFO}$ )를 기반으로 설계되었다. 제어가 어려운 반강자성을 활용하기 위해 강자성체를 위에 덧 붙인 뒤, 이를 활용해 다강체의 자기 스핀을 제어한 형 태이다. 이러한 형태의 메모리는 비휘발성, 읽기/쓰기 전압(0.1-0.3 V), 소비 에너지( $(100 \mathrm{mV}, 1 \mathrm{aJ} / \mathrm{bit})$, 오 차율 $\left(\left\langle 10^{-12}\right)\right.$ 등의 측면에서 뛰어난 성능이 검증되었다. 이처럼 현재는 반강자성/강유전성을 지니는 다강체를 기반으로만 실험적인 검증이 진행되었는데, 이는 상온 강자성/강유전 자기전기결합 다강성이 나타나는 단일상 


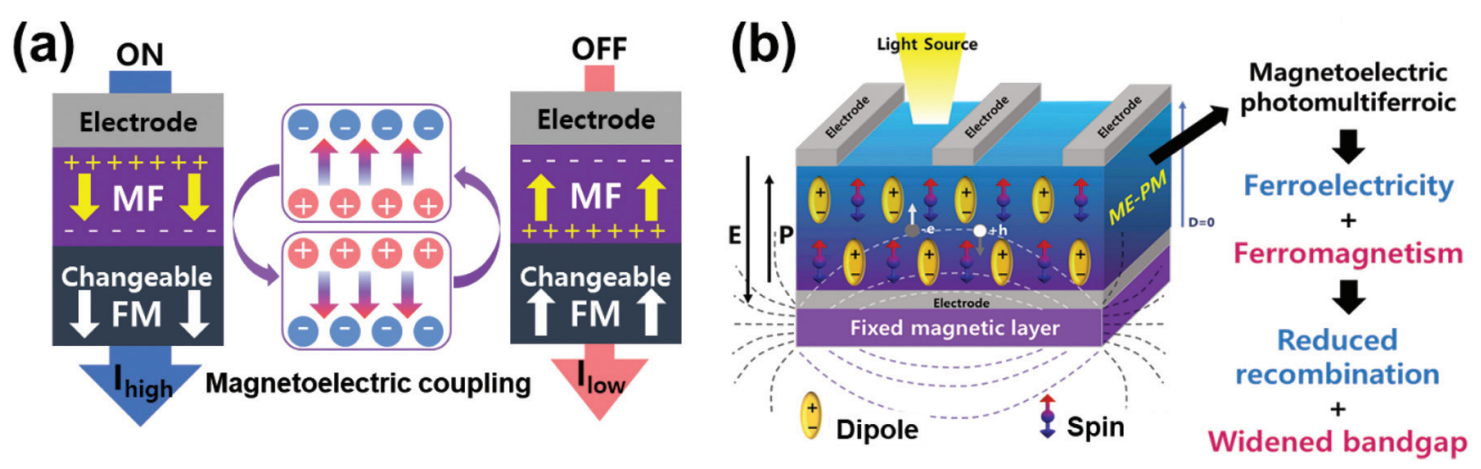

Fig. 6. Schematic illustration of (a) magnetoelectric tunnel junction including electrode, multiferroic oxides, and ferromagnet layer and (b) multiferroic photovoltaic device along with its spin and dipole behaviors.

물질이 아직 개발되지 못했기 때문이다. 소자 활용에 적 합한 자기전기 다강체가 개발된다면, 기존 실험적으로 검증된 수준보다 더 뛰어난 메모리 성능을 보여줄 수 있 을 것이라 판단된다.

강유전성을 활용하여 광발전 과정 중 발생하는 전자정공의 재결합 현상을 줄일 수 있다는 이론이 제기된 이 후로, 강유전체를 활용한 광전지 개발이 화두가 되고있 다; 재결합 현상은 광발전의 효율을 감소시키는 주 원인 중 하나로, 강유전 잔류 분극으로 에너지 장벽이 제어된 다면 이러한 현상을 완화시킬 수 있다. ${ }^{114)}$ 이러한 효용 은 실험적으로도 검증되었는데, 에너지 밴드갭에 비해 높은 개회로 전압(open circuit voltage)이 유도 가능하 다는 사실도 추가로 밝혀지며 관심을 끌고 있다. 하지만 강유전체는 기본적으로 부도체 물질이기 때문에, 광발 전에 적합한 밴드갭(band gap, $1.4 \mathrm{eV}$ )보다 훨씬 큰 값 $(>3 \sim 4 \mathrm{eV})$ 을 지니고 있다. 이로 인해 강유전체를 활 용한 광전지 개발은 난항을 겪고 있었는데, 최근 자기전 기 다강체가 강유전성을 지니면서 상대적으로 낮은 밴 드갭( $2 \mathrm{eV})$ 을 지닌다는 사실이 돌파구로 떠오르며 주 목을 받기 시작하였다 (Fig. 6(b)). ${ }^{16)}$ 또한 자기장을 활 용하여 밴드갭이 일정범위 제어가 가능하다는 사실은 다강체를 활용한 광전지 개발 연구에 활력을 불어 넣어 주었다. 자기전기 다강체를 활용한 광전지 개발은 현재 어느정도 실험적인 진척이 있지만, 아직 최적의 밴드갭 과 소자 구조 구현을 위한 연구 등이 지속되고 있는 실 정이다. 이 외에도 자기전기결합 효과를 통해 뇌신경 신
호와 근육 반응을 구현하는 인공근육과 약물 전달 시스 템 등 다양한 분야에서 활용 가능할 것이라 거론되고있 다. 하지만 이러한 분야들 또한 적절한 성능의 물질 개 발이 뒷받침 되지 않아 진전에 난항을 겪고있다.

\section{4. 결론 및 전망}

본 리뷰 논문에서는 단일상에서 강자성과 강유전성이 공존 및 결합되어있는 자기전기 다강체의 전반적인 연 구 동향에 대해 기술하였다. 전술한 바와 같이, 강성의 발현 기원에 따라 분류되는 가장 보편적인 방법(Type I , II)을 기준으로 물질 연구 개발 동향을 우선 서술하 였다. Type I 과 II 물질군은 각각 기운 반강자성(혹은 약한 강자성)과 변위형 강유전성이 공존 및 결합되어 있 는 다강체와, (반)강자성 및 이에 동반되는 스핀 유도 강 유전성을 보이는 단일상 다강체가 주를 이룬다. 반강자 성과 변위형 강유전성이 공존하는 형태의 경우, 페로브 스카이트 구조 등 기존의 강유전체 산화물을 기반으로 자성을 유도한 상당수의 물질군을 포괄한다. 이러한 물 질군은 뛰어난 강유전성을 지니고 상대적으로 높은 전 이 온도를 지니지만, 반강자성의 스핀 배열에서 오는 낮 은 활용도로 인하여 제약을 받고 있다. (반)강자성 및 이 에 동반되는 스핀 유도 강유전성을 갖는 형태의 경우, 두 강성의 발현 기원이 같기 때문에 자기전기결합 상수 가 상대적으로 높은 물질들이 포진되어 있다. 하지만 자 기 스핀 유도 강유전성의 경우, 일반적인 강유전체와 비 
교하여 강유전 자발 분극, 잔류 분극 값 등이 매우 낮다. 강자성과 강유전성의 발현 기원이 서로 상반된다고 알 려져 있음에도 불구하고, 이렇듯 자기전기 다강체 물질 의 연구 개발은 상당한 진전을 이룬 상태이다. 하지만 여전히 각각의 한계점이 명확하게 드러나기 때문에, 이 를 보완하여 상온 이상에서 강자성과 강유전성이 공존 하며 강하게 결합되어있는 단일상 다강체를 개발하려는 연구가 지속되고 있다.

다음으로는 자기전기 다강체 기반의 차세대 소자 구 현을 위한 연구개발 동향을 살펴보았다. 단일상에서 나 타나는 강자성/강유전성 자기전기결합 현상을 활용하 여, 고집적/저전력/고속 비휘발성 메모리, 고효율 광전 지, 자기장으로 제어가 가능한 생체 소자 등 다양한 차 세대 전자 소자가 이론상 제안되었고, 연구실 단위에서 일부 항목에 대한 실험적인 검증이 보고된 상태이다. 현 재까지의 차세대 소자 개발 동향을 반추하였을 때, 개발 된 다강성 물질들은 아직 소자 구현에 적합한 요건을 갖 추지 못한 실정이라는 것을 다시 한번 확인 가능했다.

이를 해결하기 위한 돌파구 중 하나로, 변위형 강유 전체에서 강자성을 유도하는 것이 가장 목표에 부합하 는 물질을 개발할 수 있는 방법이라 판단된다. 하지만 전술한 바와 같이, 페로브스카이트 구조와 같은 대부분 의 변위형 강유전체 물질은 자기 활성화 이온이 특정 자 리에만 고용되는 것을 선호하여 180 도 초교환 상호작용 이 강제된다. 즉, 대부분의 변위형 강유전체를 기반으로 하는 다강체는 반강자성을 고유 성질로 띠게 된다. 많은 연구를 통해 180 도 초교환 상호작용에서도 자기 스핀의 배열에 따라 순 자기 모멘트가 유도될 수 있는 약한 강 자성 혹은 기운 반강자성을 나타낼 수 있다는 사실이 확 인되었다. 하지만 이렇게 유도된 순 자기 모멘트의 경우 상대적으로 값이 작을 뿐 아니라, 여전히 반평행으로 배 열된 자기 스핀 배열은 제어가 힘들다는 문제점을 지니 고 있다. 따라서 이러한 한계를 극복하기 위해서는 변위 형 강유전체에서 그 강유전성을 보존하며, 90도 초교환 상호작용을 유도할 수 있는 새로운 돌파구가 필요하다 판단된다. 상온 단일상 강자성/강유전성 자기전기결합 다강체가 개발된다면, 강성의 발현 기원 및 정체된 다강
체 연구 분야가 물리학적으로 재조명되며 부흥을 일으 킬 수 있을 뿐 아니라 다양한 미래 산업 분야를 망라하 여 각광받는 물질로 활용될 수 있을 것이라 예상된다.

\section{Acknowledgement}

본 연구는 울산과학기술원 2021년 연구 기금 (1.210035.01) 및 과학기술정보통신부가 지원하 는 한국연구재단의 해외우수연구기관유치사업 (2017K1A4A3015437)의 연구비 지원을 받아 수행되었 습니다.

\section{REFERENCES}

1. M. Sugimoto, "The Past, Present, and Future of Ferrites," J. Am. Ceram. Soc., 82 [2] 269-280 (1999).

2. G. H. Haertling, "Ferroelectric ceramics: history and technology," J. Am. Ceram. Soc., 82 [4] 797818 (1999).

3. H. Kim, C. Sohn, G. T. Hwang, K. I. Park and C. K. Jeong, "(K,Na) $\mathrm{NbO}_{3}-\mathrm{LiNbO}_{3}$ nanocube-based flexible and lead-free piezoelectric nanocomposite energy harvesters," J. Korean Ceram. Soc., 57 [4] 401-408 (2020).

4. H. P. Kim, G. J. Lee, J. H. Cho, W. S. Kang, S. G. Lee, H. Y. Lee, and W. Jo, "In Situ Total Strain Measurements Revealing the Strain Mechanism of $\mathrm{Pb}\left(\mathrm{Mg}_{1 / 3} \mathrm{Nb}_{2 / 3}\right) \mathrm{O}_{3}-\mathrm{PbTiO}_{3}$ Single Crystals," $J$. Materiomics, 7 [4] 693-98 (2021).

5. Web of Science ${ }^{T M}$, https://apps.webofknowledge. com.

6. M. Fiebig, T. Lottermoser, D. Meier and M. Trassin, "The evolution of multiferroics," Nat. Rev. Mater, 1 [8] 16046 (2016).

7. N. A. Spaldin and R. Ramesh, "Advances in magnetoelectric multiferroics," Nat. Mater., 18 [3] 203-212 (2019).

8. J. H. Cho and W. Jo, "A Brief Review on Magnetoelectric Multiferroic Oxides," J. Korean Inst. Electr. Electron. Mater. Eng., 34 [3] 149-166 
(2021).

9. J. F. Scott, "Room-temperature multiferroic magnetoelectrics," NPG Asia Mater, 5 [11] e72-e72 (2013).

10. M. Fiebig and N. A. Spaldin, "Current trends of the magnetoelectric effect," The European Physical Journal B, 71 [3] 293-297 (2009).

11. T. H. O'Dell, "The electrodynamics of magnetoelectric media," Philosophical Magazine, 7 [82] 1653-1669 (1962).

12. K. F. Wang, J. M. Liu and Z. F. Ren, "Multiferroicity: the coupling between magnetic and polarization orders," Adv. Phys, 58 [4] 321448 (2009).

13. M. M. Vopson, "Fundamentals of Multiferroic Materials and Their Possible Applications," Crit. Rev. Solid State Mater., 40 [4] 223-250 (2015).

14. N. Hur, S. Park, P. A. Sharma, J. S. Ahn, S. Guha and S. W. Cheong, "Electric polarization reversal and memory in a multiferroic material induced by magnetic fields," Nature, 429 [6990] 392-395 (2004).

15. J. F. Scott, "Multiferroic memories," Nat. Mater., 6 [4] 256-257 (2007).

16. M. A. Jalaja and S. Dutta, "Ferroelectrics And Multiferroics For Next Generation Photovoltaics," Adv. Mater. Lett., 6 [7] 568-584 (2015).

17. P. Curie, "First consideration of an intrinsic correlation of magnetic and electric properties in a solid," J. Phys. Theor. Appl., 3 [3] 393-415 (1894).

18. Web of Science ${ }^{\mathrm{TM}}$ (https://apps.webofknowledge. com)

19. I. E. Dzyaloshinskii, "On the magneto-electrical effects in antiferromagnets," Sov. Phys. JETP, 10 628-629 (1960).

20. R. E. Newnham, J. J. Kramer, W. A. Schulze and L. E. Cross, "Magnetoferroelectricity in $\mathrm{Cr}_{2} \mathrm{BeO}_{4}$," J. Appl. Phys., 49 [12] 6088-6091 (1978).

21. J. Van Suchtelen, "Product Properties : A New Application of Composite Materials," Philips Res. Rep., 27 28-37 (1972).

22. J. Ryu, A. V. Carazo, K. Uchino and H. E. Kim, "Magnetoelectric Properties in Piezoelectric and Magnetostrictive Laminate Composites," Jpn. J. Appl. Phys, 40 [8R] 4948-4951 (2001).
23. J. Ryu, S. Priya, K. Uchino and H. E. Kim, "Magnetoelectric Effect in Composites of Magnetostrictive and Piezoelectric Materials," $J$. Electroceramics, 8 [2] 107-119 (2002).

24. J. Wang, J. B. Neaton, H. Zheng, V. Nagarajan, S. B. Ogale, B. Liu, D. Viehland, V. Vaithyanathan, D. G. Schlom, U. V. Waghmare, N. A. Spaldin, K. M. Rabe, M. Wuttig and R. Ramesh, "Epitaxial $\mathrm{BiFeO}_{3}$ multiferroic thin film heterostructures," Science, 299 [5613] 1719-1722 (2003).

25. T. Kimura, T. Goto, H. Shintani, K. Ishizaka, T. Arima and Y. Tokura, "Magnetic control of ferroelectric polarization," Nature, 426 [6962] 5558 (2003).

26. S. Ishiwata, Y. Taguchi, H. Murakawa, Y. Onose and Y. Tokura, "Low-Magnetic-Field Control of Electric Polarization Vector in a Helimagnet," Science, 379 [5870] 1643-1646 (2008).

27. I. Kim, Y. S. Oh, Y. Liu, S. H. Chun, J. S. Lee, K. T. Ko, J. H. Park, J. H. Chung and K. H. Kim, "Electric polarization enhancement in multiferroic $\mathrm{CoCr}_{2} \mathrm{O}_{4}$ crystals with $\mathrm{Cr}$-site mixing," Appl. Phys. Lett, 94 [4] 042505 (2009).

28. Z. Li, K. Tao, J. Ma, Z. Gao, V. Koval, C. Jiang, G. Viola, H. Zhang, A. Mahajan, J. Cao, M. Cain, I. Abrahams, C. Nan, C. Jia and H. Yan, " $\mathrm{Bi}_{3.25} \mathrm{La}$ ${ }_{0.75} \mathrm{Ti}_{2.5} \mathrm{Nb}_{0.25}\left(\mathrm{Fe}_{0.5} \mathrm{Co}_{0.5}\right)_{0.25} \mathrm{O}_{12}$, a single phase room temperature multiferroic," J. Mater. Chem. C, 6 [11] 2733-2740 (2018).

29. P. G. Radaelli, L. C. Chapon, A. Daoud-Aladine, C. Vecchini, P. J. Brown, T. Chatterji, S. Park and S. W. Cheong, "Electric field switching of antiferromagnetic domains in $\mathrm{YMn}_{2} \mathrm{O}_{5}$ : a probe of the multiferroic mechanism," Phys. Rev. Lett., 101 [6] 067205 (2008).

30. Y. J. Choi, H. T. Yi, S. Lee, Q. Huang, V. Kiryukhin and S. W. Cheong, "Ferroelectricity in an ising chain magnet," Phys. Rev. Lett., 100 [4] 047601 (2008).

31. Y. S. Chai, Y. S. Oh, L. J. Wang, N. Manivannan, S. M. Feng, Y. S. Yang, L. Q. Yan, C. Q. Jin and K. H. Kim, "Intrinsic ferroelectric polarization of orthorhombic manganites with E-type spin order," Phys. Rev. B, 85 [18] 184406 (2012).

32. C. Lu, M. Wu, L. Lin and J. M. Liu, "Single-phase multiferroics: new materials, phenomena, and 
physics," Natl. Sci. Rev., 6 [4] 653-668 (2019).

33. S. Dong, H. Xiang and E. Dagotto, "Magnetoelectricity in multiferroics: a theoretical perspective," Natl. Sci. Rev., 6 [4] 629-641 (2019).

34. N. A. Spaldin, "Multiferroics beyond electric-field control of magnetism," Proceedings of the Royal Society A: Mathematical, Physical \& Engineering Sciences website, 476 [2233] 20190542 (2020).

35. N. A. Hill, "Why Are There so Few Magnetic Ferroelectrics?," J. Phys. Chem. B, 104 [29] 66946709 (2000).

36. S. W. Cheong and M. Mostovoy, "Multiferroics: a magnetic twist for ferroelectricity," Nat. Mater, 6 [1] 13-20 (2007).

37. H. Schmid, "Magnetic ferroelectric materials," Bull. Mater. Sci., 17 [7] 1411-1414 (1994).

38. D. Khomskii, "Classifying multiferroics: Mechanisms and effects," Physics, 2 [20] (2009).

39. J. T. Heron, J. L. Bosse, Q. He, Y. Gao, M. Trassin, L. Ye, J. D. Clarkson, C. Wang, J. Liu, S. Salahuddin, D. C. Ralph, D. G. Schlom, J. Iniguez, B. D. Huey and R. Ramesh, "Deterministic switching of ferromagnetism at room temperature using an electric field," Nature, 516 [7531] 370373 (2014).

40. R. Palai, R. S. Katiyar, H. Schmid, P. Tissot, S. J. Clark, J. Robertson, S. A. T. Redfern, G. Catalan and J. F. Scott, " $\beta$ phase and $\gamma-\beta$ metal-insulator transition in multiferroic $\mathrm{BiFeO}_{3}$," Phys. Rev. B, 77 [1] 014110 (2008).

41. S. R. Burns, O. Paull, J. Juraszek, V. Nagarajan and D. Sando, "The Experimentalist's Guide to the Cycloid, or Noncollinear Antiferromagnetism in Epitaxial $\mathrm{BiFeO}_{3}$," Adv. Mater, 32 [45] 2003711 (2020).

42. Y. H. Chu, L. W. Martin, M. B. Holcomb, M. Gajek, S. J. Han, Q. He, N. Balke, C. H. Yang, D. Lee, W. Hu, Q. Zhan, P. L. Yang, A. FraileRodriguez, A. Scholl, S. X. Wang and R. Ramesh, "Electric-field control of local ferromagnetism using a magnetoelectric multiferroic," Nat. Mater., 7 [6] 478-482 (2008).

43. C. Ederer and N. A. Spaldin, "Weak ferromagnetism and magnetoelectric coupling in bismuth ferrite," Phys. Rev. B, 71 [6] 060401 (2005).
44. I. Dzyaloshinsky, "A thermodynamic theory of "weak" ferromagnetism of antiferromagnetics," J. Phys. Chem. Solids, 4 [4] 241-255 (1958).

45. T. Moriya, "New Mechanism of Anisotropic Superexchange Interaction," Phys. Rev. Lett., 4 [5] 228-230 (1960).

46. I. A. Sergienko and E. Dagotto, "Role of the Dzyaloshinskii-Moriya interaction in multiferroic perovskites," Phys. Rev. B, 73 [9] 094434 (2006).

47. H. J. Zhao, P. Chen, S. Prosandeev, S. Artyukhin and L. Bellaiche, "Dzyaloshinskii-Moriya-like interaction in ferroelectrics and antiferroelectrics," Nat. Mater., 20 [3] 341-345 (2020).

48. H. Katsura, N. Nagaosa and A. V. Balatsky, "Spin current and magnetoelectric effect in noncollinear magnets," Phys. Rev. Lett., 95 [5] 057205 (2005).

49. S. Manipatruni, D. E. Nikonov, C. C. Lin, T. A. Gosavi, H. Liu, B. Prasad, Y. L. Huang, E. Bonturim, R. Ramesh and I. A. Young, "Scalable energy-efficient magnetoelectric spin-orbit logic," Nature, 565 [7737] 35-42 (2019).

50. T. Lim, O. S. Jeon, Y. La, S. Y. Park, Y. J. Yoo and K. H. Yang, "A-site Doping Effect of Multiferroic $\mathrm{BiFeO}_{3}$ Ceramics," J. Korean Phys. Soc., 77 [11] 1021-1025 (2020).

51. N. R. Ko, J. H. Cho, J. M. Jang and W. Jo, “A-site engineering: leading weak ferromagnetism in $100(1-\mathrm{x}) \mathrm{Bi}_{0.1} \mathrm{Co}_{0.9} \mathrm{FeO}_{3}-100 \mathrm{xBa}_{0.9} \mathrm{Co}_{0.1} \mathrm{TiO}_{3}$ with superexchange interaction," J. Korean Inst. Electr. Electron. Mater. Eng., 34 [5] 386-392 (2021)

52. R. Nechache, P. Gupta, C. Harnagea and A. Pignolet, "Enhanced magnetism in epitaxial $\mathrm{BiFeO}_{3}-\mathrm{BiCrO}_{3}$ multiferroic heterostructures," Appl. Phys. Lett, 91 [22] 222908 (2007).

53. M. Xue, G. Tan, A. Xia, Z. Chai, L. Lv, H. Ren, X. Ren and J. Li, "Multi-doped bismuth ferrite thin films with enhanced multiferroic properties," Ceram. Int., 45 [10] 12806-12813 (2019).

54. P. Mandal, M. J. Pitcher, J. Alaria, H. Niu, P. Borisov, P. Stamenov, J. B. Claridge and M. J. Rosseinsky, "Designing switchable polarization and magnetization at room temperature in an oxide," Nature, 525 [7569] 363-366 (2015).

55. S. A. Khan, T. Ahmed, F. Akram, J. Bae, S. Y. Choi, T. T. Thanh, M. Kim, T. K. Song, Y. S. Sung, M. H. Kim and S. Lee, "Effect of sintering 
temperature on the electrical properties of pristine BF-35BT piezoelectric ceramics," J. Korean Ceram. Soc., 57 [3] 290-295 (2020).

56. W. Yi, Z. Lu, X. Liu, D. Huang, Z. Jia, Z. Chen, X. Wang and H. Zhu, "Relationship between chemical composition, phase structure and piezoelectric property of $\mathrm{BiFeO}_{3}-\mathrm{BaTiO}_{3}$ ceramics near morphotropic phase boundary," J. Mater. Sci.: Mater. Electron, 32 [6] 1-10 (2021)

57. M. Zhang, H. J. Yang, Y. Li, W. Q. Cao, X. Y. Fang, J. Yuan and M. S. Cao, "Cobalt doping of bismuth ferrite for matched dielectric and magnetic loss," Appl. Phys. Lett, 115 [21] 212902 (2019).

58. T. Pikula, J. Dzik, P. Guzdek, M. Kowalczyk, K. Siedliska and E. Jartych, "Magnetic and magnetoelectric properties of $\mathrm{Bi}_{0.5} \mathrm{Nd}_{0.5} \mathrm{FeO}_{3}$ ceramics," Ceram. Int., 46 [2] 1804-1809 (2020).

59. W. Hu, Y. Chen, H. Yuan, G. Li, Y. Qiao, Y. Qin and S. Feng, "Structure, Magnetic, and Ferroelectric Properties of $\mathrm{Bi}_{1-\mathrm{x}} \mathrm{Gd}_{\mathrm{x}} \mathrm{FeO}_{3}$ Nanoparticles," J. Phys. Chem. C, 115 [18] 88698875 (2011).

60. C. M. Fernandez-Posada, A. Castro, J. M. Kiat, F. Porcher, O. Pena, M. Alguero and H. Amorin, "A novel perovskite oxide chemically designed to show multiferroic phase boundary with roomtemperature magnetoelectricity," Nat. Commun., 7 [1] 12772 (2016).

61. M. Staruch, H. ElBidweihy, M. G. Cain, P. Thompson, C. A. Lucas and P. Finkel, "Magnetic and multiferroic properties of dilute Fe-doped $\mathrm{BaTiO}_{3}$ crystals," APL Mater., 8 [3] 031109 (2020).

62. D. E. Jain Ruth, R. A. U. Rahman, M. Dhamodaran, V. Lakshmanan, S. Balasubramanian, P. Schmid-Beurmann, P. Zhou, G. Srinivasan and M. Ramaswamy, "Room temperature magnetoelectric coupling in Fe-doped sodium bismuth titanate ceramics," J. Alloys Compd., 830154679 (2020).

63. K. Shalini, S. Pappachan, A. Mayeen, N. Kalarikkal and N. V. Giridharan, "Strengthened magnetoelectric multiferroic response in $\left(\mathrm{K}_{0.5} \mathrm{Na}_{0.5}\left[\mathrm{Nb}_{1-\mathrm{x}} \mathrm{Fe}_{\mathrm{x} / 2} \mathrm{Mn}_{\mathrm{x} / 2}\right] \mathrm{O}_{3}\right)$ ceramics," Mater. Lett., 261126988 (2020).
64. L. Chen, A. A. Bokov, W. Zhu, H. Wu, J. Zhuang, N. Zhang, H. N. Tailor, W. Ren and Z. G. Ye, "Magnetoelectric relaxor and reentrant behaviours in multiferroic $\mathrm{Pb}\left(\mathrm{Fe}_{2 / 3} \mathrm{~W}_{1 / 3}\right) \mathrm{O}_{3}$ crystal," Sci. Rep., 6 [1] 1-7 (2016).

65. L. F. Henrichs, O. Cespedes, J. Bennett, J. Landers, S. Salamon, C. Heuser, T. Hansen, T. Helbig, O. Gutfleisch, D. C. Lupascu, H. Wende, W. Kleemann and A. J. Bell, "Multiferroic Clusters: A New Perspective for Relaxor-Type Room-Temperature Multiferroics," Adv. Funct. Mater., 26 [13] 2111-2121 (2016).

66. A. Levstik, V. Bobnar, C. Filipič, J. Holc, M. Kosec, R. Blinc, Z. Trontelj and Z. Jagličić, "Magnetoelectric relaxor," Appl. Phys. Lett, 91 [1] 012905 (2007).

67. J. H. Cho, J. H. Lee, H. S. Jang, N. J. Lee, W. S. Kang, G. T. Hwang, S. H. Kim, M. G. Kim, W. Jo, "Room temperature magnetoelectric coupling in $\mathrm{Pb}\left(\mathrm{Fe}_{1 / 2} \mathrm{Nb}_{1 / 2}\right) \mathrm{O}_{3}$ by counterbalancing imbalanced spin moments through spin canting," J. Appl. Phys., 130 [9] (2021).

68. C. Zener and R. R. Heikes, "Exchange Interactions," Rev. Mod. Phys., 25 [1] 191-198 (1953).

69. H. Xiang, C. Lee, H. J. Koo, X. Gong and M. H. Whangbo, "Magnetic properties and energymapping analysis," Dalton Trans., 42 [4] 823-853 (2013).

70. J. Kanamori, "Superexchange interaction and symmetry properties of electron orbitals," J. Phys. Chem. Solids, 10 [2-3] 87-98 (1959).

71. J. B. Goodenough, "Covalent Exchange vs Superexchange in Two Nickel Oxides," J. Solid State Chem., 127 [1] 126-127 (1996).

72. B. Aurivillius, "Mixed Bismuth Oxides with Layer Lattices," Arki for Kemi, 1463 (1949).

73. J. Bobic, M. Vijatovic-Petrovic and B. Stojanovic, "Aurivillius $\mathrm{BaBi}_{4} \mathrm{Ti}_{4} \mathrm{O}_{15}$ based compounds: Structure, synthesis and properties," Processing and Application of Ceramics, 7 [3] 97-110 (2013).

74. A. Moure, "Review and Perspectives of Aurivillius Structures as a Lead-Free Piezoelectric System," Applied Sciences, 8 [1] (2018).

75. J. Liu, Z. Shen, H. Yan, M. J. Reece, Y. Kan and P. Wang, "Dielectric, piezoelectric, and ferroelectric 
properties of grain-orientated $\mathrm{Bi}_{3.25} \mathrm{La}_{0.75} \mathrm{Ti}_{3} \mathrm{O}_{12}$ ceramics," J. Appl. Phys., 102 [10] 104107 (2007).

76. D. Y. Suárez, I. M. Reaney and W. E. Lee, "Origin of Ferroelectricity in Aurivillius Compounds," MRS Online Proc. Libr., 658 [1] 1191-1196 (2000).

77. D. H. Kim, J. Y. Han and C. W. Bark, "Effect of the Sintering Temperature on the Structure and Properties of Fe-doped $\mathrm{Bi}_{3.25} \mathrm{La}_{0.75} \mathrm{Ti}_{2} \mathrm{O}_{12}$ Ceramics," Mol. Cryst. Liq. Cryst., 621 [1] 129135 (2015).

78. X. Y. Mao, W. Wang and X. B. Chen, "Electrical and magnetic properties of $\mathrm{Bi}_{5} \mathrm{FeTi}_{3} \mathrm{O}_{15}$ compound prepared by inserting $\mathrm{BiFeO}_{3}$ into $\mathrm{Bi}_{4} \mathrm{Ti}_{3} \mathrm{O}_{12}$," Solid State Commun., 147 [5-6] 186-189 (2008).

79. H. Maiwa, N. Iizawa, D. Togawa, T. Hayashi, W. Sakamoto, M. Yamada and S.-i. Hirano, "Electromechanical properties of Nd-doped $\mathrm{Bi}_{4} \mathrm{Ti}_{3} \mathrm{O}_{12}$ films: A candidate for lead-free thin-film piezoelectrics," Appl. Phys. Lett., 82 [11] 17601762 (2003).

80. A. Srinivas, M. M. Kumar, S. V. Suryanarayana and T. Bhimasankaram, "Investigation of dielectric and magnetic nature of $\mathrm{Bi}_{7} \mathrm{Fe}_{3} \mathrm{Ti}_{3} \mathrm{O}_{21}$," Mater. Res. Bull., 34 [6] 989-996 (1999).

81. A. Srinivas, D. W. Kim, K. S. Hong and S. V. Suryanarayana, "Study of magnetic and magnetoelectric measurements in bismuth iron titanate ceramic- $\mathrm{Bi}_{8} \mathrm{Fe}_{4} \mathrm{Ti}_{3} \mathrm{O}_{24}$," Mater. Res. Bull., 39 [1] 55-61 (2004).

82. M. A. Zurbuchen, R. S. Freitas, M. J. Wilson, P. Schiffer, M. Roeckerath, J. Schubert, M. D. Biegalski, G. H. Mehta, D. J. Comstock, J. H. Lee, Y. Jia and D. G. Schlom, "Synthesis and characterization of an $n=6$ Aurivillius phase incorporating magnetically active manganese, $\mathrm{Bi}_{7}(\mathrm{Mn}, \mathrm{Ti})_{6} \mathrm{O}_{21}$," Appl. Phys. Lett, 91 [3] 033113 (2007).

83. L. Keeney, T. Maity, M. Schmidt, A. Amann, N. Deepak, N. Petkov, S. Roy, M. E. Pemble, R. W. Whatmore and D. Johnson, "Magnetic Field-Induced Ferroelectric Switching in Multiferroic Aurivillius Phase Thin Films at Room Temperature," J. Am. Ceram. Soc., 96 [8] 23392357 (2013).

84. Z. Li, J. Ma, Z. Gao, G. Viola, V. Koval, A.
Mahajan, X. Li, C. Jia, C. Nan and H. Yan, "Room temperature magnetoelectric coupling in intrinsic multiferroic Aurivillius phase textured ceramics," Dalton Trans., 45 [36] 14049-14052 (2016).

85. M. G. Song, J. Y. Han and C. W. Bark, "Effects of Doping Ratio of Cobalt and Iron on the Structure and Optical Properties of $\mathrm{Bi}_{3.25} \mathrm{La}_{0.75} \mathrm{Fe}_{(\mathrm{x})} \mathrm{Co}_{(1-\mathrm{x})}$ $\mathrm{Ti}_{2} \mathrm{O}_{12}(\mathrm{X}=0,0.25,0.5,0.75,1), " J$. Nanosci. Nanotechnol., 15 [10] 7841-7844 (2015).

86. W. Wang, J. Lu, Y. Yin, J. Wang, X. Chen, X. Mao and $\mathrm{Y}$. Lu, "Multiferroic properties of high Curie temperature $\mathrm{Bi}_{6} \mathrm{Fe}_{1.4} \mathrm{Ni}_{0.6} \mathrm{Ti}_{3} \mathrm{O}_{18}$ ceramics," Jpn. J. Appl. Phys, 58 [7] 075510 (2019).

87. Z. Yu, X. Meng, Z. Zheng, Y. Lu, H. Chen, C. Huang, H. Sun, K. Liang, Z. Ma, Y. Qi and T. Zhang, "Room temperature multiferroic properties of rare-earth-substituted Aurivillius phase $\mathrm{Bi}_{5} \mathrm{Ti}_{3} \mathrm{Fe}_{0.7} \mathrm{Co}_{0.3} \mathrm{O}_{15}$ ceramics," Mater. Res. Bull., 115 235-241 (2019).

88. M. Li, H. Tan and W. Duan, "Hexagonal rare-earth manganites and ferrites: a review of improper ferroelectricity, magnetoelectric coupling, and unusual domain walls," Phys. Chem. Chem. Phys., 22 [26] 14415-14432 (2020).

89. B. B. Van Aken, T. T. M. Palstra, A. Filippetti and N. A. Spaldin, "The origin of ferroelectricity in magnetoelectric $\mathrm{YMnO}_{3}$, , Nat. Mater., 3 [3] 164170 (2004).

90. D. Y. Cho, J. Y. Kim, B. G. Park, K. J. Rho, J. H. Park, H. J. Noh, B. J. Kim, S. J. Oh, H. M. Park, J. S. Ahn, H. Ishibashi, S. W. Cheong, J. H. Lee, P. Murugavel, T. W. Noh, A. Tanaka and T. Jo, "Ferroelectricity driven by $\mathrm{Y} \mathrm{d}^{0}$-ness with rehybridization in $\mathrm{YMnO}_{3}$," Phys. Rev. Lett., 98 [21] 217601 (2007).

91. N. Ikeda, H. Ohsumi, K. Ohwada, K. Ishii, T. Inami, K. Kakurai, Y. Murakami, K. Yoshii, S. Mori, Y. Horibe and H. Kito, "Ferroelectricity from iron valence ordering in the charge-frustrated system $\mathrm{LuFe}_{2} \mathrm{O}_{4}$," Nature, 436 [7054] 1136-1138 (2005).

92. M. Angst, R. P. Hermann, A. D. Christianson, M. D. Lumsden, C. Lee, M. H. Whangbo, J. W. Kim, P. J. Ryan, S. E. Nagler, W. Tian, R. Jin, B. C. Sales and D. Mandrus, "Charge order in $\mathrm{LuFe}_{2} \mathrm{O}_{4}$ : antiferroelectric ground state and coupling to magnetism," Phys. Rev. Lett., 101 [22] 227601 
(2008).

93. K. T. Ko, H. J. Noh, J. Y. Kim, B. G. Park, J. H. Park, A. Tanaka, S. B. Kim, C. L. Zhang and S. W. Cheong, "Electronic origin of giant magnetic anisotropy in multiferroic $\mathrm{LuFe}_{2} \mathrm{O}_{4}$," Phys. Rev. Lett., 103 [20] 207202 (2009).

94. J. A. Mundy, C. M. Brooks, M. E. Holtz, J. A. Moyer, H. Das, A. F. Rebola, J. T. Heron, J. D. Clarkson, S. M. Disseler, Z. Liu, A. Farhan, R. Held, R. Hovden, E. Padgett, Q. Mao, H. Paik, R. Misra, L. F. Kourkoutis, E. Arenholz, A. Scholl, J. A. Borchers, W. D. Ratcliff, R. Ramesh, C. J. Fennie, P. Schiffer, D. A. Muller and D. G. Schlom, "Atomically engineered ferroic layers yield a room-temperature magnetoelectric multiferroic," Nature, 537 [7621] 523-527 (2016).

95. S. Fan, H. Das, A. Rebola, K. A. Smith, J. Mundy, C. Brooks, M. E. Holtz, D. A. Muller, C. J. Fennie, R. Ramesh, D. G. Schlom, S. McGill and J. L. Musfeldt, "Site-specific spectroscopic measurement of spin and charge in $\left(\mathrm{LuFeO}_{3}\right)_{\mathrm{m}} /$ $\left(\mathrm{LuFe}_{2} \mathrm{O}_{4}\right)_{1}$ multiferroic superlattices," Nature communcations, 11 [1] 5582 (2020).

96. M. Matsubara, S. Manz, M. Mochizuki, T. Kubacka, A. Iyama, N. Aliouane, T. Kimura, S. L. Johnson, D. Meier and M. Fiebig, "Magnetoelectric domain control in multiferroic $\mathrm{TbMnO}_{3}$," Science, 348 [6239] 1112-1115 (2015).

97. B. Lorenz, "Hexagonal Manganites- $\left(\mathrm{RMnO}_{3}\right)$ : Class (I) Multiferroics with Strong Coupling of Magnetism and Ferroelectricity," ISRN Condensed Matter Physics, 2013 1-43 (2013).

98. T. Aoyama, K. Yamauchi, A. Iyama, S. Picozzi, K. Shimizu and T. Kimura, "Giant spin-driven ferroelectric polarization in $\mathrm{TbMnO}_{3}$ under high pressure," Nat. Commun., 5 [1] 4927 (2014).

99. T. Kimura, "Magnetoelectric Hexaferrites," Аnпи. Rev. Condens. Matter Phys., 3 [1] 93-110 (2012).

100. K. Zhai, Y. Wu, S. Shen, W. Tian, H. Cao, Y. Chai, B. C. Chakoumakos, D. Shang, L. Yan, F. Wang and Y. Sun, "Giant magnetoelectric effects achieved by tuning spin cone symmetry in Y-type hexaferrites," Nat. Commun., 8 [1] 519 (2017).

101. Y. Kitagawa, Y. Hiraoka, T. Honda, T. Ishikura, H. Nakamura and T. Kimura, "Low-field magnetoelectric effect at room temperature," Nat.
Mater., 9 [10] 797-802 (2010).

102. T. Kimura, G. Lawes and A. P. Ramirez, "Electric polarization rotation in a hexaferrite with longwavelength magnetic structures," Phys. Rev. Lett., 94 [13] 137201 (2005).

103. K. Zhai, D. S. Shang, Y. S. Chai, G. Li, J. W. Cai, B. G. Shen and Y. Sun, "Room-Temperature Nonvolatile Memory Based on a Single-Phase Multiferroic Hexaferrite," Adv. Funct. Mater., 28 [9] 1705771 (2018).

104. Y. Yamasaki, S. Miyasaka, Y. Kaneko, J. P. He, T. Arima and Y. Tokura, "Magnetic reversal of the ferroelectric polarization in a multiferroic spinel oxide," Phys. Rev. Lett., 96 [20] 207204 (2006).

105. J. H. Cho, S. Cho, J. H. Lee, H. Palneedi, J. H. Lee, H. P. Kim, N. J. Lee, S. Tigunta, S. Pojprapai, S. Kim, J. Ryu, Y. S. Oh, S. Hong and W. Jo, "Room-temperature multiferroicity in $\mathrm{NiFe}_{2} \mathrm{O}_{4}$ and its magnetoelectric coupling intensified through defect engineering," $\mathrm{J}$. Am. Ceram. Soc., online published (2021), https://doi. org/10.1111/jace.18012.

106. A. Sundaresan and N. V. Ter-Oganessian, "Magnetoelectric and multiferroic properties of spinels," J. Appl. Phys., 129 [6] 060901 (2021).

107. S. Ghara, N. V. Ter-Oganessian and A. Sundaresan, "Linear magnetoelectric effect as a signature of long-range collinear antiferromagnetic ordering in the frustrated spinel $\mathrm{CoAl}_{2} \mathrm{O}_{4}$," Phys. Rev. B, 95 [9] 094404 (2017).

108. J. K. Dey, A. Chatterjee, S. Majumdar, A. C. Dippel, O. Gutowski, M. v. Zimmermann and S. Giri, "Ferroelectric order associated with ordered occupancy at the octahedral site of the inverse spinel structure of multiferroic $\mathrm{NiFe}_{2} \mathrm{O}_{4}$," Phys. Rev. B, 99 [14] 144412 (2019).

109. V. G. Ivanov, M. V. Abrashev, M. N. Iliev, M. M. Gospodinov, J. Meen and M. I. Aroyo, "Shortrange B-site ordering in the inverse spinel ferrite $\mathrm{NiFe}_{2} \mathrm{O}_{4}$," Phys. Rev. B, 82 [2] 024104 (2010).

110. U. G. Jong, C. J. Yu, Y. S. Park and C. S. Ri, "First-principles study of ferroelectricity induced by $\mathrm{p}-\mathrm{d}$ hybridization in ferrimagnetic $\mathrm{NiFe}_{2} \mathrm{O}_{4}$," Phys. Lett. A, 380 [40] 3302-3306 (2016).

111. G. T. Lin, Y. Q. Wang, X. Luo, J. Ma, H. L. Zhuang, D. Qian, L. H. Yin, F. C. Chen, J. Yan, R. 
R. Zhang, S. L. Zhang, W. Tong, W. H. Song, P. Tong, X. B. Zhu and Y. P. Sun, "Magnetoelectric and Raman spectroscopic studies of singlecrystalline $\mathrm{MnCr}_{2} \mathrm{O}_{4}$," Phys. Rev. B, 97 [6] 064405 (2018).

112. T. Kimura, Y. Sekio, H. Nakamura, T. Siegrist and A. P. Ramirez, "Cupric oxide as an induced-

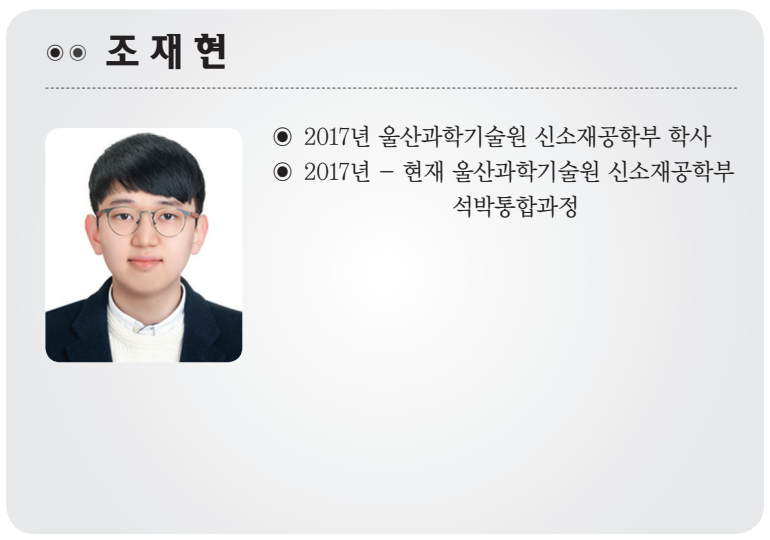

multiferroic with high-TC," Nat. Mater., 7 [4] 291-294 (2008).

113. M. Bibes and A. Barthélémy, "Towards a magnetoelectric memory," Nat. Mater., 7 [6] 425 426 (2008).

114. H. Huang, "Ferroelectric photovoltaics," Nat. Photonics, 4 [3] 134-135 (2010).

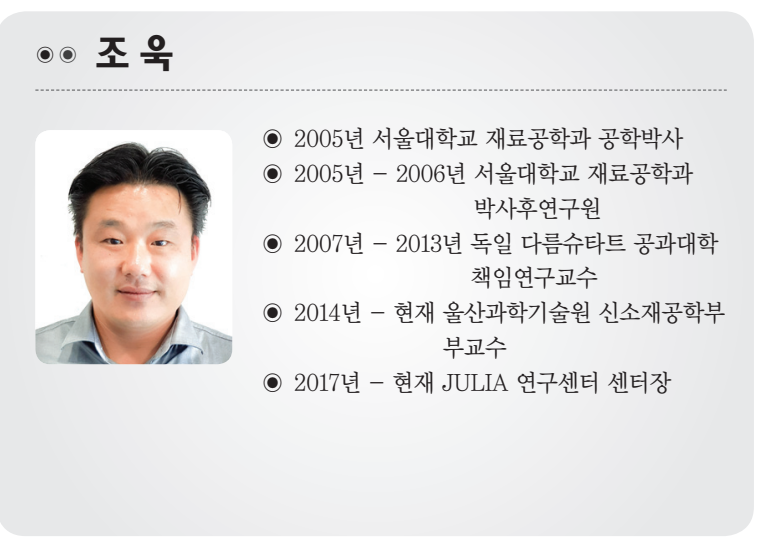

